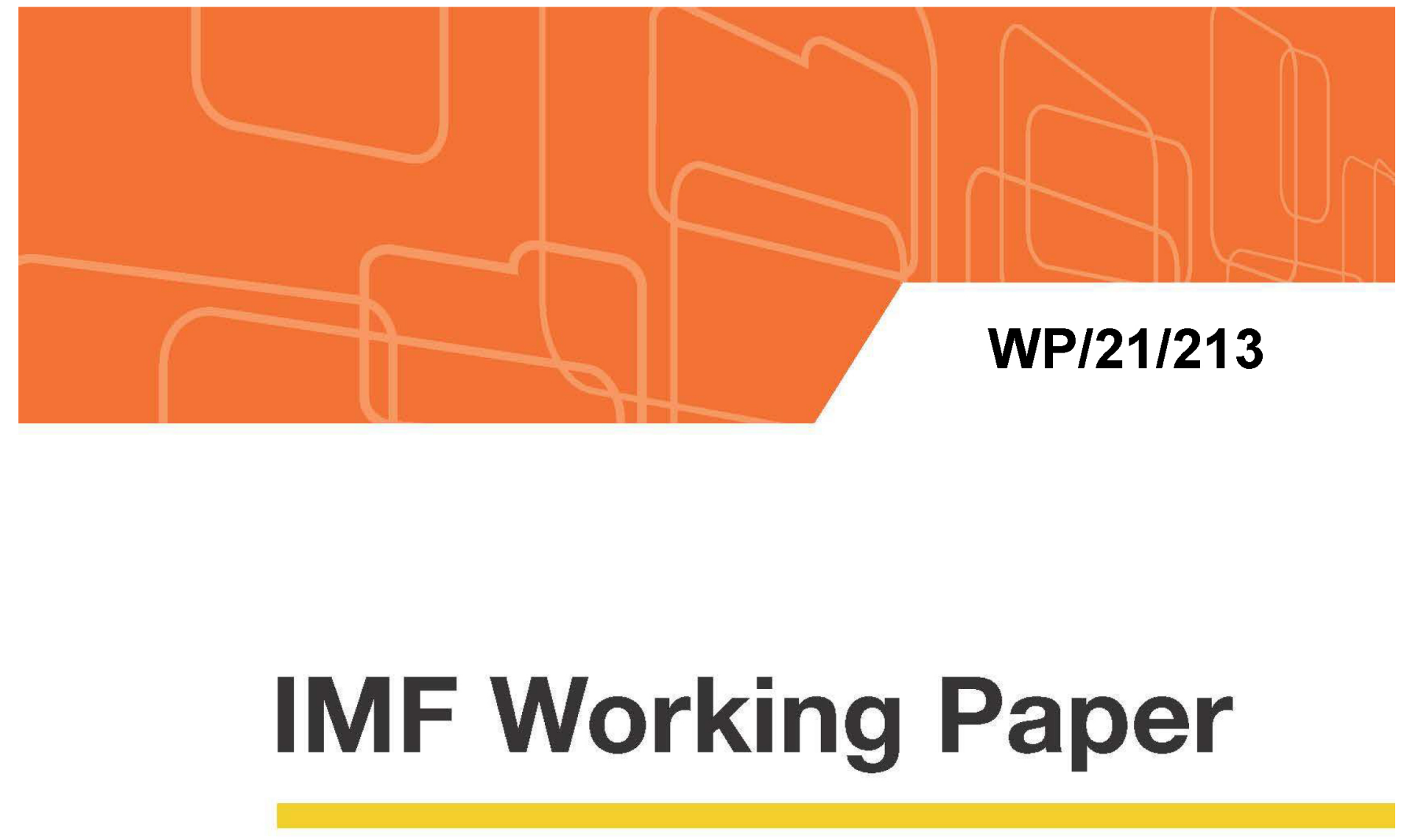

\title{
The Impact of Environmental Policy on Innovation in Clean Technologies
}

by Johannes Eugster

IMF Working Papers describe research in progress by the author(s) and are published to elicit comments and to encourage debate. The views expressed in IMF Working Papers are those of the author(s) and do not necessarily represent the views of the IMF, its Executive Board, or IMF management.

I N T E R N A T I O N A L M O N E T A R Y F U N D 


\title{
IMF Working Paper
}

Research Department

\section{The Impact of Environmental Policy on Clean Innovation}

\section{Prepared by Johannes Eugster ${ }^{1}$}

Authorized for distribution by Oya Celasun

August 2021

IMF Working Papers describe research in progress by the author(s) and are published to elicit comments and to encourage debate. The views expressed in IMF Working Papers are those of the author(s) and do not necessarily represent the views of the IMF, its Executive Board, or IMF management.

\begin{abstract}
This paper studies the effect of climate change mitigating policies on innovation in clean energy technologies. Results suggest that the tightening of environmental policies since the early 1990s have made a statistically and economically significant contribution to the increase in clean innovation. These effects generally materialized quickly, within 2 to 3 years of the policy change, and were driven by individually significant marginal effects of both market-based policies - such as feed-in tariffs and trading schemes - as well as non-market policies, such as R\&D subsidies or emission limits. Looking at electricity innovation in particular, the paper finds that the estimated effect on total innovation is positive on net, meaning that increased innovation in clean and grey technologies is not offset by a decrease in innovation in dirty technologies. From a policy point of view, the paper's results call for strong policy efforts to decisively shift innovation towards clean technologies.
\end{abstract}

JEL Classification Numbers: Q54, Q55, O32

Keywords: Climate change mitigation, innovation, environmental policies

Author's E-Mail Address: jeugster@imf.org; johannes.eugster@snb.ch;

${ }^{1}$ With special thanks for the helpful comments and discussions to Oya Celasun and Florence Jaumotte. 


\section{INTRODUCTION}

Relative to most other economic issues, climate change is slow-moving. Actions (e.g. carbon emissions) and consequences (e.g. related damages) can be several decades apart. Simulations of the macroeconomic impacts of climate change are thus typically estimated over relatively longtime spans. This makes the evolution of slow-moving variables, such as technological progress, unusually important ${ }^{2}$. Put simply, if climate-friendly alternatives become as cheap and efficient as dirty technologies, the energy transition can be done at relatively low costs in terms of growth and inclusiveness $^{3}$. If on the other hand, clean technologies remain significantly more expensive, greater, and costlier policy efforts would be needed to tilt spending toward them.

From a social planner's point of view, the objective should be to (i) avoid future climate-change related damages by reducing net carbon emissions, while (ii) minimizing transitional costs, including by stimulating technological progress among clean technologies ${ }^{4}$. This paper focuses on how climate policies can induce innovation; an issue which has recently been object of a dynamic, though mostly theoretical, literature.

Traditional integrated assessment models such as Nordhaus (1994) or Nordhaus and Boyer (2000), treated technology as exogenous - e.g. growing at a given rate - thus providing no scope for technology-enhancing effects of climate policies. This exogeneity assumption was relaxed by Nordhaus (2002), Popp (2004) and Bosetti et al. (2009), Golosov et al. (2014) and Hassler et al. (2020) among others. This line of research modeled investments into knowledge-inducing technologies and thus opened the possibilities for climate policies to induce innovation. In these models, the endogenous response of innovation generally significantly improved welfare outcomes but had a more limited effect on carbon emission or the optimal policy choice for reducing them. Golosov et al. (2014) for example show that in a reasonably general setting, the optimal carbon tax does not depend on assumptions on technology and can fully offset the pollution externality. Even if technology is endogenous, it provides adequate incentives for innovation in clean technologies and makes additional R\&D subsidies unnecessary in a first-best situation $^{5}$. In their model, innovation policies, such as R\&D subsidies however become important, both from a climate and welfare point of view, if such an optimal carbon tax cannot be imposed. ${ }^{6}$

\footnotetext{
${ }^{2}$ Another unusually important parameter is the discount rate, which is however largely outside the considerations discussed in this paper. For a more general discussion of the importance of discounting see Heal (2017), or Acemoglu et al. (2012) for its relevance for innovation policies more specifically.

${ }^{3}$ Tavares (forthcoming) for example shows that climate mitigating policies, absent compensatory measures, are likely to disproportionally affect lower income households, who in many countries tend to have a more energy intensive consumption basket and are more likely to be employed in carbon-intensive sectors.

${ }^{4}$ The need for policy interventions is generally based on a subset of various market failures, e.g. related to the externalities of pollution and knowledge creation, possible network effects and economies of scale.

${ }^{5}$ In the first-best situation of the model by Golosov et al. (2014), the carbon tax is used to address the climate externality while the R\&D subsidies are used to address the R\&D externality. Particularly high R\&D subsidies for clean technologies are thus not needed as long as carbon is taxed at the optimal rate and the R\&D externality is not stronger than in other technologies.

${ }^{6}$ In Golosov et al. (2014) and related models, technology affects welfare through the interaction between marginal costs and the degree of substitution of different sources of energy. If the elasticity of substitution is high, a small cost advantage of fossil fuels (differences in marginal
} 
The role of technology and innovation policies further gains importance, including for emissions, in models where technology is not only endogenous, but also marked by important path dependencies. In Acemoglu et al. (2012, 2016), Fried (2018) or Barrett (2021), the dependence of technological progress on market size creates positive returns to scale. If innovation today increases the size of the market, the partially fixed expenses for research become more profitable, setting off a virtuous cycle. The path dependencies in research can strengthen the case for R\&D subsidies as a complement to an optimal carbon tax to promote an early switching to cleaner energy sources. ${ }^{7}$

The recent theoretical literature thus highlights the potential of innovation to play an important role in future climate policy discussions. With the current state of climate policies nowhere near what an optimum could look like, innovation is likely relevant both for emissions as well as welfare outcomes. Yet how much innovation reacts to different climate policies is still quite poorly understood. From a theoretical point of view, choices on the characterization of the energy market (e.g. elasticities of substitution) as well as the costs and payoffs of knowledge creation matter. Independently of the care with which these coefficients are chosen, the question is partly of empirical nature.

This paper thus studies the link between climate change policies and innovation empirically. It investigates (i) whether and to what extent the overall tightening of policies has contributed to clean energy-related innovation, (ii) how more detailed policies vary in terms of innovation performance and (iii) whether potential gains in terms of clean innovation are offset by a reduction of innovation related to other technologies. To answer these questions, the paper relies on a panel estimation with different environmental policy indices and an innovation proxy based on patent applications. A quick glance at aggregate series suggests a clear positive correlation between the average tightness in environmental policy and global innovation in energy-related climate-change mitigating (CCM) technologies (Figure 1). However, it is equally obvious that other relevant factors, such as oil prices or overall innovation, have changed substantially during the observed period.

Distinguishing the effect of policy changes from other possible determinants of clean innovation is thus a challenge. In this paper, country- and year-fixed effects control both for constant countryspecific as well as time-varying global factors. In combination with other control variables, including overall patenting across all technologies, these increase the precision of the identification. Factors such as the effect of commodity prices, global economic conditions, but also education and innovation policies or different and changing patenting culture are controlled

\footnotetext{
costs) leads to large difference in energy output and allows the slightly cheaper technology to dominate the market. In such a situation, carbon prices would be all the more compelling, as already a small tax could lead to significant quantity differences.

7 The quantitative implications of an endogenous reaction of technology can be substantial. In a recent simulation by the IMF (2020), a plausible sensitivity of innovation to a gradually rising carbon price combined with an R\&D subsidy, could cut by half the price level necessary to achieve an emission target compatible with a 2-degree global warming. Combined with an initial green investment push, this would result in moderate global output losses in the near-term but much more substantial income gains from avoided climate damage in the second half of the century and beyond.
} 
for. While the paper cannot credibly instrument policy changes, the rich set of control variables and fixed effects help reduce the risk that the estimated coefficients are biased by unobserved determinants.

The paper's main conclusions are three-fold. First, tightening environmental policies made a statistically and economically significant contribution to increased innovation in clean technologies. At the aggregate level, the results suggest that the change in the average environmental policy stance (across countries) between 1990 and 2010 had an effect roughly equivalent to a permanent increase in oil prices of USD 70 per barrel. Based on a dynamic analysis, the paper shows that the effects of such a tightening materialize rather quickly, as effects become statistically significant almost immediately and strengthen over the first 2 to 3 years after the policy change.

Second, distinguishing between different technologies, the paper finds that both market policies (including trading schemes and feed-in tariffs) as well as non-market policies (including emission limits (e.g. on power plants) and R\&D subsidies) made positive, statistically significant and roughly comparable contributions to clean innovation ${ }^{8}$. This remains true if all others policy tools are controlled for. Such a result is encouraging in two ways. It first confirms that market mechanisms are effective at stimulating innovation, consistent with models of endogenous technological change, where the expected future demand for a product can incentivize research into producing it more efficiently. Results however also suggest a degree of substitutability ${ }^{9}$ among policy tools, at least as far as innovation is concerned, and that multiple policy tools - or a combination thereof - can promote clean innovation in a comparable way.

Finally, the paper looks at whether environmental policies induce additional innovations or merely change its composition towards cleaner alternatives. Focusing on electricity related technologies only, the paper finds that policies contributed to a shift in the composition of innovation away from dirty towards clean as well as "grey" technologies. This suggests that the technological improvements necessary to curb climate change will not only come from entirely new green technologies, but also from increased carbon efficiency of a priori dirty technologies. Results further provide little evidence that such an increase was offset by a decrease in dirty innovation as

\footnotetext{
${ }^{8}$ The effects of carbon prices are not statistically significant. While this is counter to a widely accepted idea that carbon prices are among the most efficient policy tools (also in terms of incentivizing innovation), it is empirically not surprising. As will be discussed further below, carbon taxes were used by a small minority of countries in our sample. As a result, the empirically exploitable variation in the data is very limited.

${ }^{9}$ A complementary analysis investigates interaction effects between policy tools to see whether there are complementarities among them. Given the lack of consistency and robustness at the aggregate level, results are not reported.
} 
the estimated effect on total electricity innovation is net positive. The fact that clean innovation is additional and does not replace innovation in potentially dirty technologies likely decreases the emission-reducing effect of a given policy ${ }^{10}$. Yet, to the extent that the additional innovation translates into faster technological progress, this also reduces the macro-economic cost of the energy transition and likely strengthens the political feasibility of a more ambitious climate agenda.

The paper is not the first attempt to study the effects of environmental policies on innovation. The most closely related paper is Johnstone et al. (2010). Similar to our paper, it analyses in a crosscountry setup the effects of broad policy measures on climate-change mitigating innovation. Many other papers have investigated the drivers of clean innovation in more narrowly defined setups. These, as well as Johnstone et al. (2010), generally provide support for the idea that clean innovation can be "induced" by environmental policies. Aghion et al. (2016) for example finds that higher tax-inclusive fuel prices have shifted innovation in the automobile sector towards cleaner technologies. Newell et al. (1999) finds similar results for energy-using consumer durables. Popp (2006) shows that innovation inducing effects can also come from non-market policies, such as more stringent sulfur dioxide (SO2) or nitrogen dioxide (NOX) standards. Adding a dynamic framework, Popp (2002) finds that similarly positive effects of energy prices on innovation (in the US energy market) materialize swiftly, but are also temporary, given diminishing returns to energy research over time. ${ }^{11}$

The main contribution of this paper is the empirical investigation of how clean innovation reacts to policy indicators at different levels of aggregation in a cross-country setup. Such an empirical setup seems particularly valuable when studying climate change, which is best addressed by an internationally coordinated effort ${ }^{12}$ and will likely involve a combination of different policy tools. An additional benefit relative to country- and sector specific analyses, is that the inclusion of country- as well as time-fixed effects can better distinguish the effects of policies from other potential drivers. The richer set of fixed effects is also one of the key advantages relative to Johnstone et al. (2010), who use a similar cross-country setup with different policy indicators. As will be shown below, accounting for time varying patenting behavior as well as global factors such as commodity prices can be a substantial advantage. Relative to Johnstone et al. (2010), this paper also uses a more standardized policy classification ${ }^{13}$, which allows an analysis at different levels of policy aggregation (e.g. individual policy types vs overall policy indicator), as well as a larger set of technologies, including not only renewable energy but also technologies related to improved efficiency in energy generation, transmission and distribution. Finally, this analysis benefits from

\footnotetext{
${ }^{10}$ Continued innovation in dirty technologies, even if slower than among clean one, reduces the cost competitiveness of the latter and thus slows the energy transition.

${ }^{11}$ For earlier work on drivers of environmental innovation see also Jaffe and Stavins (1995) and Lanjouw and Mody (1996).

${ }^{12}$ See Hassler et al. (2020) for a discussion of how "hold-outs" by some countries, which do not impose an otherwise global carbon tax, affect the cost of limiting the global temperature increase.

${ }^{13}$ The OECD's measures for Environmental Policy Stringency (EPS) is hierarchical and standardized index of policy stringency. The resulting indices reflect the relative stringency over time and across countries. While the index value is not comparable across policy tools, the common construction allows the comparison of contributions across times or the effects of changes relative to the historical distribution.
} 
a much more recent sample ${ }^{14}$, which allows it to better capture the dramatic increase in clean innovation of the early $2000 \mathrm{~s}$, as well as the flattening and partial reversal since $2010^{15}$.

The rest of the paper is structured as follows. Section 2 presents the construction of the key data series as well as the conceptual and empirical frameworks. Section 3 presents the results, focusing first on the long-run and dynamic effects of the aggregate EPS indicator. It then distinguishes between different types of policies. For both the aggregate and more detailed indicators it illustrates the magnitude of the contribution to clean innovation with counterfactual simulations. The results section concludes by illustrating how the effects differ between clean, grey, and dirty innovation related to electricity. Sensitivity analyses, discussed in Section 4 and largely reported in the appendix, show that the results are robust, e.g. to different choices regarding the measure of innovation and the empirical specifications. Section 5 concludes.

\section{DATA ANd The CONCEPTUAL ANd EMPIRICAl FrameWORKS}

\section{A. Data and Descriptive Statistics}

The key link of investigation is how environmental policies affect the flow of innovation in a sample of 33 OECD countries from 1990 to $2016^{16}$. This subsection illustrates the construction and dynamics of the two main variables of interest and briefly presents the other relevant series.

Innovation is proxied by the number of climate-change mitigating patent families, associated with a particular country and year. This measure is constructed in two steps, by (i) associating each patent family with a country and year and (ii) checking whether their technology codes justifies them to be considered "clean".

The number of patent families is identified based on information from the PATSTAT database, collected and administered by the European Patent Office (EPO). Rather than counting every individual application, the count relies on the "patent family", which groups different application for the same invention all over the world ${ }^{17}$. Making the patent family the unit of account of our innovation proxy assures that each technology is only counted once and reduces the risk that the estimated effect is biased by strategic patenting behavior, which can lead to increased patent counts

\footnotetext{
${ }^{14}$ The sample in Johnstone et al. (2010) is limited to 25 countries over the time frame of 1978-2003, while our sample covers 33 countries from 1990-2016.

${ }^{15}$ For a discussion of possible reasons behind the relative decline in clean innovation post-2010, see Acemoglu et al. (2019) and Popp et al. (2020). According to the latter, a partial relaxation in environmental standards in some countries, technological progress especially related to hydraulic fracturing, energy prices and reduced investor appetite after a possible technology bubble in the previous years may have all contributed to diminished returns to clean research.

${ }^{16}$ The countries include Australia, Austria, Belgium, Brazil, Canada, China, Czech Republic, Germany, Denmark, Finland, France, Greece, Hungary, Indonesia, India, Ireland, Italy, Japan, Korea, Netherlands, Norway, Poland, Portugal, Russia, Slovakia, Slovenia, Spain, Sweden, Switzerland, Turkey, the United Kingdom, the USA and South Africa.

${ }^{17}$ Since patent jurisdictions are national, inventions are often patented in multiple countries. In addition, patents can be refined after an initial application is made. In some cases, the combination of these two factors can result in hundreds or even thousands of applications that all relate to the same technology. The EPO's DOCDB simple patent family classification is used.
} 
without additional knowledge creation ${ }^{18}$. The patent family is associated with the year in which a first application was made ${ }^{19}$ and the most common country of residence of the first inventors ${ }^{20}$.

A priori, a disadvantage of relying on the patent family count is that it does not control for the economic or technological value of the innovation, which can be related to differences in the propensity of the innovator to patent a given innovation. In the empirical specification, this issue is largely being addressed by the combined inclusion of total innovation (working as a denominator) as well as country- and time fixed effects. Controlling for total innovation captures country-specific changes in the patenting culture that are common across sectors (e.g. due to changes in patenting procedures or innovation policies). The country- and year fixed effects respectively absorb drivers in the technology-specific patenting that are either constant across time or time-varying but common for all countries. To further establish the robustness of our framework, sensitivity analyses will show that the main results are not sensitive to either a broader (e.g. all applications) or a narrower innovation count (e.g. "international" patent families, having applications in at least two countries) ${ }^{21}$.

Having associated innovation to countries and a moment in time, the next step involves the selection of clean technologies. For this, the paper uses two types of classification. The first, proposed by Haščič and Migotto (2015), identifies various environment-related technologies (ERT) based on precise technological codes as defined in the patent applications. Their classification is used to construct the patent counts for "climate change mitigation technologies related to energy generation, transmission or distribution", our proxy for "clean energy innovation". The second classification relies on Dechezleprêtre et al. (2017) to identify different types of innovation related to electricity technologies. The authors distinguish between dirty and clean innovation, relating respectively to fossil fuel combustion and alternative energy sources, as well as "grey" technologies, which improve the pollution efficiency of dirty ones.

The analysis focuses on clean technologies related to energy, rather than looking at climate-change mitigating technologies irrespective of the application ${ }^{22}$. This is done for three reasons. First, the

\footnotetext{
${ }^{18} \mathrm{~A}$ bias from strategic patenting could occur if companies decide to strategically expand intellectual propriety protection for technologies that had been created previously. Since what Marina Kurakina (video) considers "strategic" applications are more likely to be "continuation patents", the use of patent families at least partially reduce this risk.

${ }^{19}$ The first year of the first application in a family is generally referred to as the "priority date" and is the year when an innovation is reflected in our dataset.

${ }^{20} \mathrm{We}$ associate the innovation to the country of residence of the inventor (rather than the applicant), as this is a better proxy for who created the knowledge, rather than who owns it. Given that a patent family can be composed of multiple applications, we rely on the most common country of residence among the first inventors, which - mentioned first - are generally understood as having made the biggest intellectual contribution.

21 "Triadic" patent families are another popular measure that counts only technologies that have applications at the European, Japanese as well as at the US patent office. However, Japan has rather unusual filing requirements (e.g. regarding language, representation, prior art), which for nonJapanese companies likely present higher hurdles than the requirements of other patent offices. This likely biases such counts in favor of Japanese inventors. Possibly more important, the more stringent the "quality requirement", the higher the share of zeroes one gets in the patent count $(10 \%$ zeroes with "international" patent family, but $44 \%$ with "triadic"). While the count models still keep these observations in the sample, the nevertheless reduce the degree of variation the estimation can exploit.

${ }^{22}$ The ERT database identifies three other types of climate-change mitigating technologies: i) those related to transportation, ii) to building and iii) to the capture, storage, sequestration, or disposal of greenhouse gases. The main results largely extent to technologies related to transportation, but only partially / not at all to the ones related GHG / transportation (not reported, but available on request). This is hardly a surprise as for the latter, the link between local EPS policies and research incentive are much less clear. E.g. the manufacturing of transportation equipment is highly concentrated in global value chains, where local incentives likely play a very limited role.
} 


\section{Figure 2: Share of Clean Electricity Innovation}
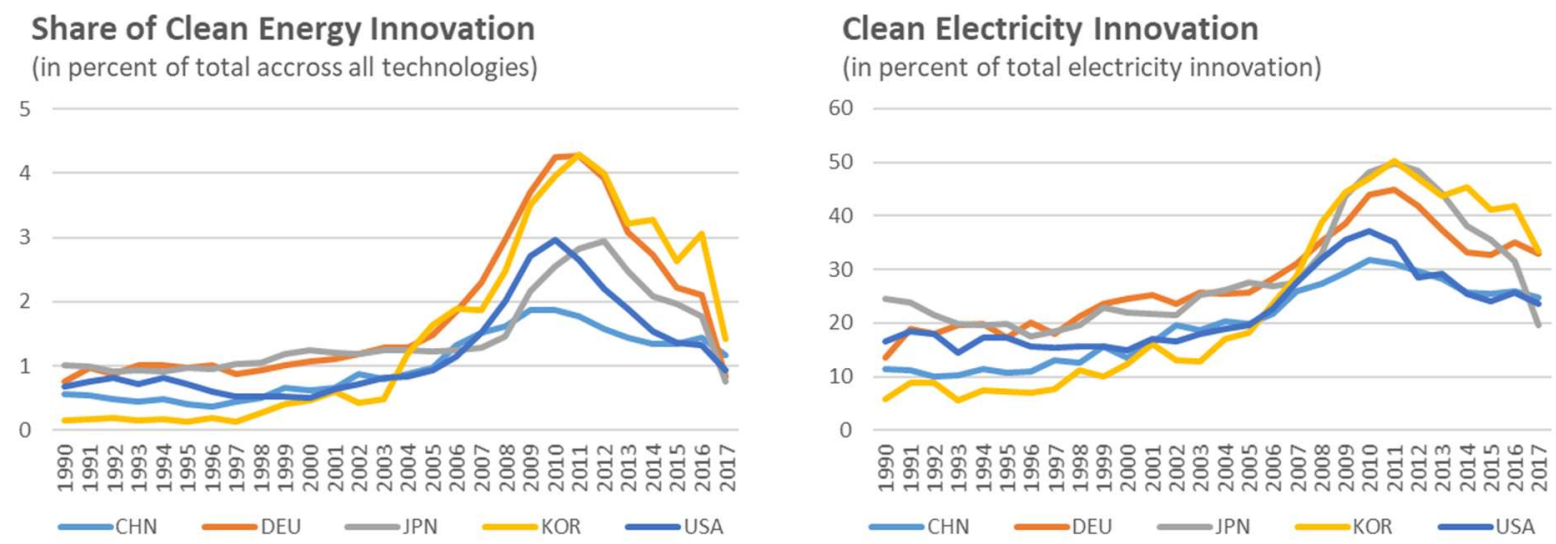

Source: PATSTAT, author's calculations

energy sector is particularly affected - if not directly targeted - by many climate change mitigating policies captured by the EPS measure. Second, according to the IPCC (Bruckner et al. 2014), the energy supply sector was with 35\% the largest contributor of global GHG emissions in 2010, of which almost $3 / 4$ was attributable to the production of electricity and heat. Third, energy has been a major and particularity dynamic source of clean innovation. In our sample, the average share of total climate mitigating innovation that was related to energy increased from $16 \%$ in 1990 to $35 \%$ in 2010 .

The graphs in Figure 2 respectively show the evolution of clean energy innovation (as a share of total innovation across all technologies) and clean electricity innovation (as a share of total electricity innovation). As has been reported elsewhere (e.g. Acemoglu et al. 2019), the share of clean energy innovation (left) increased dramatically in the early 2000 s, peaked however towards the end of the first decade and has significantly declined in most countries since then. Looking more closely at different types of electricity innovation (right) shows that this tendency was less driven by a shift in innovation between broad technologies (e.g. out of energy technologies overall), but by an increase and subsequent decline in the clean share of innovation within the broader technological group.

The question why innovation declined after 2010 is still in search for a definite answer. Acemoglu et al (2019) highlight the importance of the shale gas revolution. Popp and others (2020) also point to the possible role of an earlier clean-tech bubble and falling returns on clean innovation. While other factors appear to have contributed to this reversal, the results from this paper support the hypothesis that the stringency of environmental policies, which peaked roughly at the same time as clean innovation, likely played a role too. The relevant environmental policy variable is described next.

To proxy for the stringency of climate policies, which is the key variable of interest, the paper uses the Environmental Policy Stringency (EPS) data from the OECD. The EPS indicator, initially 
proposed by Botta and Kozluk (2014), aggregates the assessments of detailed policies over 4 hierarchical levels. The most aggregate EPS indicator can be decomposed into market- and nonmarket policies, and further into taxes, trading-schemes and feed-in tariffs on one hand (market policies $^{23}$ ) and emissions limits and R\&D subsidies on the other (non-market policies). Each of these policies can again be broken down, e.g. depending on what exactly is being taxed, traded, or regulated.

At the most disaggregated level, the indicator attributes a value to each country year depending on its stringency relative to the rest of the sample. A zero is attributed if the policy tool is not used and 6 if it is among the most stringent uses. The thresholds in between are chosen based on the insample distribution of values on each instrument. Subsequent aggregations are done by simple averages (see Botta and Kozluk (2014) for more details).

These standardized policy measures provide a methodologically coherent set of indicators, reflecting a country's policy stringency relative to the rest of the sample. Though as the scoring depends on how stringently a policy tool has been used among other countries, a certain value of one indicator - or change therein - cannot be compared to the same value of another indicator. The illustrative comparisons across indicators (in Section 3B) are thus done by contrasting the effects of movements on their distribution (e.g. from the $10^{\text {th }}$ to the $90^{\text {th }}$ percentile) or changes therein (e.g. between 1990 and 2010). While this makes the estimated effect independent of the scale (as doubling the indicator would reduce by half the coefficient), it cannot overcome the fact that neither absolute nor relative changes in the policy indicators can be translated into a common benchmark, such as $\mathrm{CO} 2$ emission reductions or carbon-tax-equivalent USD amounts.

Figure 3 illustrates the evolution of the stringency and popularity of the different policy tools. What stands out is that on average there has been a clear trend towards more stringent regulation, but that the scope and underlying drivers of the change vary greatly across the different policy tools. Limits (e.g. on NOx, SOx or PMx emissions; or on the Sulphur content in Diesel) tightened substantially and gradually but had already been used by the overwhelming majority of countries in the early 1990s. The same pattern can be observed - though less clearly - for R\&D subsidies ${ }^{24}$. Their use contrasts sharply with market-based policies. Trading schemes and feed-in tariffs were only rarely used in the early 1990s and the average overall stringency reflects in part their increased popularity among policy makers (rather than a gradual tightening of policies already in place). The use of carbon taxes on the other hand remained very sporadic until the end of the sample. Their very limited uptake and variation likely explain - as illustrated later - the empirical estimation's

\footnotetext{
${ }^{23}$ An earlier version also included deposit and refunds schemes, which were however dropped due to data constraints as the data set was extended to the BRICS countries in 2015. See OECD (2016) for more details.

${ }^{24}$ A higher score for R\&D subsidies reflects more generous support in percent of GDP, whereas higher scores for feed-in tariffs, trading schemes or emission limits reflects higher prices, stricter requirements, or a combination thereof.
} 
failure to produce significant effects of carbon taxes, counter to what one would expect from theoretical contributions. ${ }^{25}$

Figure 3: Stringency and Use of Climate Change Policy Tools
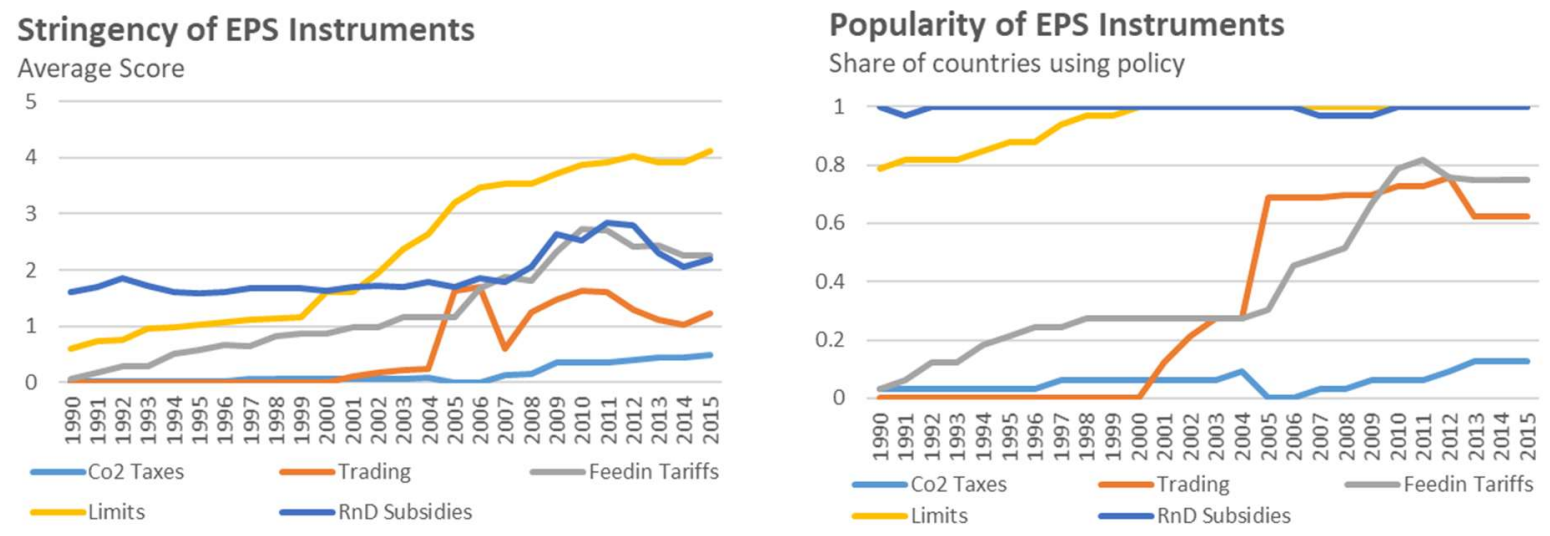

Source: OECD, author's calculations

Figure 4: Environmental Policy Stringency Across Countries
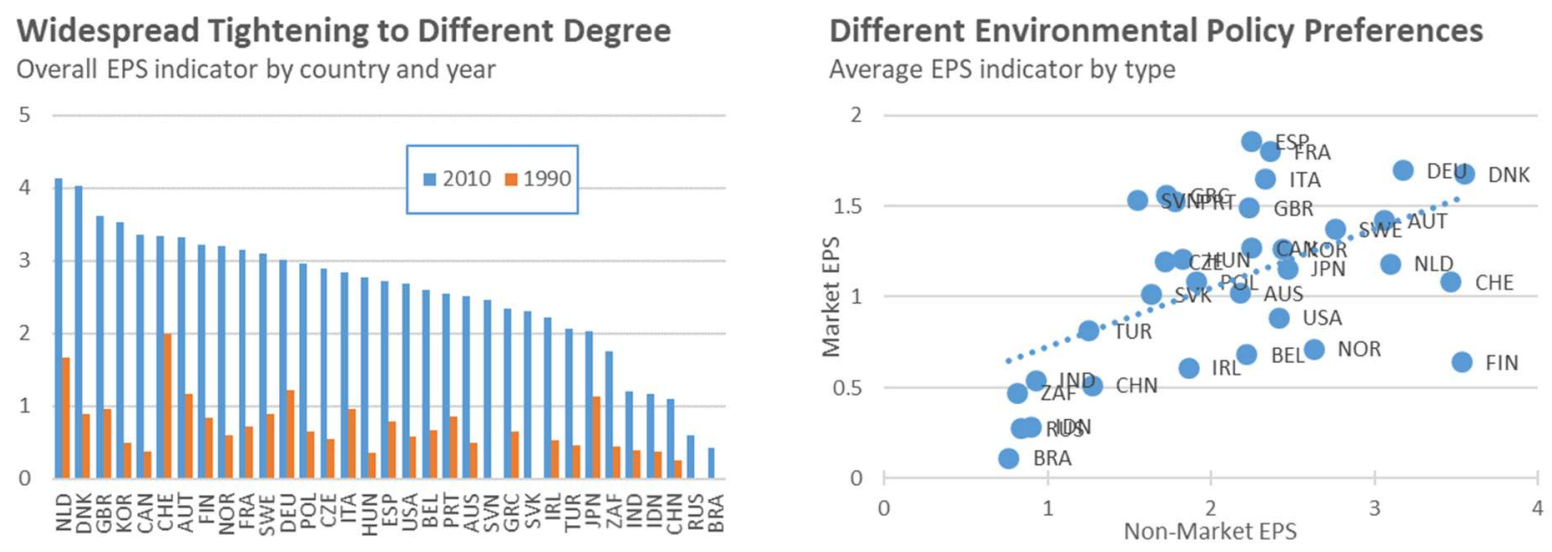

Source: OECD, author's calculations

The general increase in stringency has been widespread. In our sample, all countries tightened their overall environmental policies, yet to different degree (Figure 4, left). Northern and Western European countries, as well as Korea and Canada, have generally been most ambitious. In 2010, many emerging markets on the other hand still had more lenient environmental policies. Countries also differ in the type of policies they have applied (Figure 4, right). Most of the emerging markets in the sample have performed relatively better in their non-market policies (including emission limits and R\&D subsidies) but have been slower to tighten their market-based policies. The same is true for countries such as Switzerland or Finland, yet at the other end of the scale. Many southern

\footnotetext{
${ }^{25}$ Data on environmental policy stringency exists up to 2014 , which - given a one-period lag in the regression - limits the estimation sample to 2015.
} 
European countries on the other hand had comparatively higher market-EPS scores, given generally more ambitious policies related to trading schemes and feed-in tariffs.

\section{B. Conceptual and Empirical Framework}

The conceptual basis for the empirical estimation is a multiplicative production function of innovation in country $i$ and time $t$ along the lines of the one specified in Acemoglu et al. (2016).

$$
X_{i, t}=\theta_{i, t}\left(H_{i, t}\right)^{\beta}\left(u_{i, t}\right)^{\gamma}
$$

... where $u_{i, t}$ stands for the accessible stock of knowledge and $H_{i, t}$ stands for the research effort. The equation can be re-written in a way that can be estimated with empirical count models.

$$
X_{i, t}=\exp \left(\alpha_{i}+\delta_{t}+\beta \ln \left(H_{i, t}\right)+\gamma \ln \left(u_{i, t}\right)+\epsilon_{i, t}\right)
$$

$\ldots$ where $\theta_{i, t}=\exp \left(\alpha_{i}+\delta_{t}\right), \alpha_{i}$ and $\delta_{t}$ respectively are country- and time-fixed effects, and $\epsilon_{i, t}$ is the residual,

The estimation relies on a conditional fixed effects Poisson model with robust standard errors, an estimator that is widely recognized for its robustness ${ }^{26}$. Consistent with the conceptual framework, the baseline includes the technology-specific stock of knowledge ${ }^{27}$ as well as overall innovation. The latter controls for policies related to education and research or changes in patenting culture ${ }^{28}$. While data availability is sometimes a constraint, other control variables used in the various specifications include the following:

- $\quad$ Proven oil and gas reserves proxy for the country-specific supply of fossil fuels ${ }^{29}$. This is particularly relevant for the US, where the development of the hydro-fracking technology has boosted the supply of fossil fuels since the mid-2000s.

- Electricity prices at the household level proxy for market-based incentives for innovation. Higher electricity prices likely make it easier for more expensive clean technologies to penetrate the market, which makes related R\&D investments more profitable.

\footnotetext{
${ }^{26}$ Wooldridge (1999) for example shows that the consistency and asymptotic normality of the estimator depends only on the conditional mean assumption, not however on assumptions regarding higher moments. This provides robustness even if the underlying distribution is mis-specified. From a more practical point of view, the fixed effects Poisson model is attractive also given the ease with which fully robust variance matrix can be calculated. In addition, the fixed effects allow for individual-specific intercepts (variation in conditional mean), which sets it apart from the fixed effect negative binomial, where the fixed effects control for country specific dispersion parameters.

${ }^{27}$ The stock of knowledge is constructed as the discounted sum of total patent applications. A discount rate of $10 \%$ and the perpetual inventory method are used.

${ }^{28}$ The incentives to patent a given technology differ across countries, but also change over time. For example, patent promotion policies or (historically) different patent requirement have resulted in a relative inflation in the numbers of applications in some countries. The inclusion of overall patenting controls for such differences.

${ }^{29} \mathrm{Crude}$ oil and natural gas reserves are taken from https://www.eia.gov/international/data/world. In order to translate gas reserves, reported in trillion cubic feet (tcf), into the billion barrels equivalents, the industry rule of thumb of 1 barrel of oil $=6,000$ cubic feet of natural gas is used. Coal reserves, though also relevant for electricity generation in many countries, are not included given insufficiently long time-series for our country sample. To the extent data exists, the variation over time was however more muted than in oil and gas reserves, particularly among the main innovator countries in ERT.
} 
- $\quad$ Product and labor market regulations, such as the electricity specific ETCR indicator from the OECD as well as the labor market stringency indicator from the Fraser Institute's Economic Freedom of the World database are controlled for in some specifications ${ }^{30}$. Increased competition and lower regulatory barriers can potentially create additional incentives to innovate. Particularly the labor regulation variable however significantly constrains the sample; it is also not specifically energy related.

- $\quad$ Crude oil prices proxy for global changes in the supply and demand for fossil fuels ${ }^{31}$. Given its global nature, this variable is generally absorbed by year-fixed effects and used mainly to make an illustrative comparison of the economic importance of the effect of innovation.

With very few exceptions, all specifications include both country- as well as year-fixed effects. These control respectively for time-invariant country characteristics, as well common dynamics, including the effects of the global economic and financial conditions or commodity prices. The combination of country- and year- fixed effects assures that the identification of the policy coefficient is based on the relative variation across countries over time and not drive, e.g. by a common trend towards tighter environmental standards. All control variables are lagged by one year to account for time lags in the knowledge production.

\section{RESULTS}

This section presents the results. It starts by showing that environmental policies, captured by the aggregate index, significantly stimulate clean innovation. These effects are economically sizeable, materialize relatively quickly and are highly insensitive to different specifications. The following two subsections show respectively that (i) most of the more detailed policy tools are supporting the strong aggregate effects and that (ii) the stimulus in clean innovation is not offset by a decline in innovation related to more traditional technologies.

\section{A. The Effects of Environmental Policy Overall}

Table 1 presents the estimated effects of a tightening of environmental policies on clean energy innovation across various specifications. In addition to the technology-specific knowledge stock and total innovation (across all technologies), the different specifications respectively include the evolution of oil and gas reserves (column 2), electricity prices at the household level (column 3),

\footnotetext{
${ }^{30}$ While a higher ETCR indicator stands for more stringent product market regulation, the opposite is true for the Economic Freedom Index used to proxy labor market regulation. See http://www.oecd.org/economy/reform/indicators-of-product-market-regulation/ and https://www.fraserinstitute.org for more details.

${ }^{31}$ While oil is itself not a major fuel for electricity generation, its price has the advantage of being highly graspable by the public and comparable across regions and over time. Prices for natural gas vary considerably across regions, but generally correlate substantially with the oil price. Coal prices on the other hand are substantially less standardized as they vary not only across regions, but also by rank, grade, and mining method. See https://www.eia.gov/energyexplained/hydrocarbon-gas-liquids/prices-for-hydrocarbon-gas-liquids.php and https://www.eia.gov/energyexplained/oil-and-petroleum-products/prices-and-outlook.php for more information.
} 
indicators for labor and electricity market regulation (column 4) or combinations thereof (columns 5 and 6).

The estimated effects of the environmental policy stringency are positive, highly statistically significant, and reasonably stable, ranging from 0.15 to 0.25 . The control variables have the expected sign and are often also statistically significant. As expected, the available knowledge stock, total innovation as well as the price of electricity are positive and statistically significant, mostly at the $1 \%$ level. Less stringent product market regulation in the electricity sector (a lower value of the ETCR score) also tends to support innovation, but the coefficient loses significance in the most complete specification in column (6) ${ }^{32}$. The coefficient on oil and gas reserves is not statistically significant, but it has the expected sign and will become more relevant when looking at the different types of electricity innovation in subsection $\mathrm{C}$. The coefficient on labor market regulation is equally insignificant and even changes sign between the specifications. This is not surprising, as the labor regulation is not specific to the energy sector; and the conceptual link to innovation is less compelling.

Table 1: Aggregate Effect of Environmental Policy on Clean Innovation

(1) (2) (3) (4) (5)

Dependent variables: CCM Energy patent families

\begin{tabular}{lcccccc} 
& $0.184 * * *$ & $0.249 * * *$ & $0.188 * * *$ & $0.232 * * *$ & $0.166^{* * *}$ & $0.203 * * *$ \\
L.EPS & $(4.46)$ & $(6.25)$ & $(6.77)$ & $(6.74)$ & $(5.18)$ & $(5.48)$ \\
L.ln(tech stock) & $0.600^{* * *}$ & $0.744 * * *$ & $0.507 * * *$ & $0.632 * * *$ & $0.552 * * *$ & $0.479 * *$ \\
& $(9.73)$ & $(10.30)$ & $(11.47)$ & $(6.31)$ & $(21.77)$ & $(4.93)$ \\
L.In(all tech) & $0.415 * * *$ & $0.320^{* * *}$ & $0.573 * * *$ & $0.574 * * *$ & $0.165 *$ & $0.452 * * *$ \\
& $(6.70)$ & $(4.04)$ & $(5.98)$ & $(4.39)$ & $(1.70)$ & $(2.66)$ \\
L.ln(oil \& gas reserves, bb) & & $-0.136^{*}$ & & -0.122 & & -0.131 \\
& & $(-1.66)$ & & $(-1.29)$ & & $(-1.41)$ \\
L.ln(electr. price HH, USD) & & & $0.295 * * *$ & $0.180^{*}$ & & $0.357 * *$ \\
& & & $(3.24)$ & $(1.84)$ & & $(3.52)$ \\
L.ETCR electricity & & & & & $-0.105 * *$ & -0.0615 \\
& & & & & $(-2.56)$ & $(-1.16)$ \\
L. Labor market reg. (EFW) & & & & & 0.0152 & -0.0394 \\
& & & & & $(0.69)$ & $(-1.35)$ \\
\hline Country FE & Yes & Yes & Yes & Yes & Yes & Yes \\
Year FE & Yes & Yes & Yes & Yes & Yes & Yes \\
N & 781 & 743 & 608 & 579 & 424 & 352 \\
\hline
\end{tabular}

Note: The table reports coefficients and t statistics from a fixed effects Poisson estimation of clean energy innovation on the environmental policy indicator and controls. Country- and year-fixed effects are always included. EPS = environmental policy stringency; tech stock = patent stock in specific technology, all tech = total patenting in all technologies. Robust standard errors. $* \mathrm{p}<0.10, * * \mathrm{p}<0.05, * * * \mathrm{p}<0.01$

\footnotetext{
${ }^{32}$ Electricity price are negatively correlated to the tightness of product market regulation. It is not implausible that a price-reducing effect of liberalization is behind the multi-collinearity and the reduced statistical significance of the ETCR coefficient.
}

14 
As data availability is more uneven for some of the variables (particularly for EMs), the inclusion of additional controls rapidly reduces the size of the sample. Column 1 is hence used as the baseline specification. Compared to the other columns, the coefficient of the EPS variable is towards the lower end of the range, which suggests that its choice as baseline does not exaggerate the effects of environmental policies.

The effects of environmental policies are not only statistically, but also economically significant. To illustrate this, we compare clean energy innovation predicted in 2010 using the actual EPS value, with the one predicted had the EPS indicator not changed since $1990^{33}$. This comparison suggests that the change in the EPS directly contributed roughly 30 percent of the increase in clean energy innovation between 1990 and $2010^{34}$. Based on an illustrative estimation which includes oil prices (but no year-FE), the effect of tightening environmental policies was roughly equivalent to a USD 70 increase in the price of crude oil per barrel. As the common trend towards tighter environmental regulation is absorbed by the year-FE, it is not implausible that the actual effect is even higher than implied by the coefficient. In addition, a positive effect of policies on innovation today leads to a bigger knowledge stock tomorrow, which - given its positive coefficient - further increase the effect on innovation. The magnitude of such second-round effects however appears to be of second-order importance.

The positive effect on innovation also materializes very quickly. In order to illustrate this, the baseline specification is estimated in a local projection model, the popular method pioneered by Jordà (2005) and used in similar form by Stock and Watson (2007), Auerbach and Gorodnichenko (2013) and others. The model estimates the impulse response function over an expanding horizon as a function of a change in the policy indicator in time $t=0\left(\Delta E P S_{i, t}\right)$ and a series of controls $\left(X_{i, t}\right)$, as in the following equation.

$$
y_{i, t+k}-y_{i, t-1}=\alpha_{i}+\beta \Delta E P S_{i, t}+\gamma X_{i, t}+\delta \text { year }+\varepsilon_{i, t}
$$

The main difference with respect to column (1) of Table 1 is that instead of year-fixed effects, a trend plus the $\log$ of oil prices are included ${ }^{35}$. Country-fixed effects, additional EPS shocks between $t$ and $t+j$, as well as three lags of the shocks and growth of clean innovation are included but not reported for brevity. ${ }^{36}$

The results in Table 2 illustrate that the positive effects on innovation start to materialize already in the year the tightening in environmental policy becomes effective. The size of the coefficient

\footnotetext{
${ }^{33}$ The comparison excludes the global components captured by the year fixed effects from both predicted values.

${ }^{34}$ The policy contribution is assessed by comparing the predicted values, excluding year-fixed effects, when using respectively the 1990 ad the 2010 values of environmental regulation. A back-of-the envelope calculation, which regresses the retrieved year-fixed effects on oil prices and the EPS suggests that the contribution of the policy contribution to the year-FE is also approximately one third.

${ }^{35}$ This choice is made as the combination of year-fixed effects and log-differences absorbs too much variation.

${ }^{36}$ The inclusion of shocks before and after time $t$ is crucial to ensure that the identified effect is not compounded by policy changes that precede or follow the change in $\mathrm{t}=0$. Similarly, the lags of clean innovation are included to differentiate the effect of policies from the ones of the time series proprieties of the dependent variable. The inclusion of such controls is consistent with the literature (e.g. Furceri et al. 2019, Bouis et al. 2020), but results are robust to reasonable changes in the lag length.
} 
Table 2: The Dynamics of the Effect
(1)
(2)
(3)
(4)
(5)

Dependent variables: Log-Difference in CCM Energy patent families between $\boldsymbol{t}+\mathbf{1}$ and $\boldsymbol{t}+\boldsymbol{j}$

\begin{tabular}{lccccc} 
& $\boldsymbol{t}$ & $\boldsymbol{t}+\mathbf{1}$ & $\boldsymbol{t}+\mathbf{2}$ & $\boldsymbol{t}+\mathbf{3}$ & $\boldsymbol{t}+\mathbf{4}$ \\
$\Delta \mathrm{EPS}$ & $0.106^{* * *}$ & $0.126^{* *}$ & $0.140^{*}$ & 0.117 & 0.114 \\
& $(2.78)$ & $(2.05)$ & $(1.80)$ & $(1.06)$ & $(1.04)$ \\
L.ln(tech stock) & $-0.199^{* * *}$ & $-0.351^{* * *}$ & $-0.492^{* * *}$ & $-0.586^{* * *}$ & $-0.658^{* * *}$ \\
& $(-4.29)$ & $(-4.28)$ & $(-4.47)$ & $(-5.10)$ & $(-5.69)$ \\
$\ln$ (oil price) & $0.222^{* * *}$ & $0.376^{* * *}$ & $0.340 * * *$ & $0.295^{* * *}$ & 0.147 \\
& $(3.86)$ & $(4.30)$ & $(3.32)$ & $(2.90)$ & $(1.23)$ \\
$\Delta \ln ($ all tech) & $0.545^{* * *}$ & $0.428^{* *}$ & $0.372 *$ & $0.388^{*}$ & $0.394 * *$ \\
& $(4.30)$ & $(2.47)$ & $(1.76)$ & $(1.93)$ & $(2.96)$ \\
\hline $\mathrm{N}$ & 649 & 616 & 584 & 552 & 520 \\
$\mathrm{r} 2$ & 0.285 & 0.289 & 0.339 & 0.387 & 0.422 \\
\hline
\end{tabular}

Note: The table reports coefficients and $t$ statistics from a fixed-effects panel regression of the log-change in clean energy innovation between $t-1$ and $t+j$ on an environmental policy indicator and controls. $\Delta \ln ($ all tech) refers to the log difference of total patenting over the same period. Country-fixed effects, a trend, the values of the EPS indicator between $t$ and $t+j$, as well as three lags of both the EPS and the growth of overall innovation are included but not reported for brevity. $E P S=$ environmental policy stringency; tech stock = patent stock in specific technology. Robust standard errors. ${ }^{*} \mathrm{p}<0.10,{ }^{* *} \mathrm{p}<0.05, * * * \mathrm{p}<0.01$

increases further for another two years, to about $3 / 4$ of the baseline coefficient from Table 1 , before becoming too imprecise to be statistically distinguished from zero. Overall innovation and the oil price have the expected sign and are generally highly significant. The coefficient on the knowledge stock in clean energy technology however has the opposite sign than in Table 1 . This is to be expected as innovation growth tends to be particularly high if a technology is new but tends to slow as it matures ${ }^{37}$.

The speed with which innovation picks up, relative to the year preceding the tightening in environmental standards, may appear excessively fast. In part, this is due to the timing convention of the patent count. Inventors often make a first patent application as soon as a sufficiently precise idea of the technology is available. The "priority date" defines the start of the intellectual property even if the claim is refined or geographically enlarged subsequently ${ }^{38}$. One should however not conclude that technological progress would materialize equally quickly. Only few patents lead to commercial breakthroughs. And even for those who do, there are generally significant lags between the first patent application and the commercial availability of the technology, let alone a

\footnotetext{
${ }^{37}$ Akcigit \& Kerr (2018) for example find that impact of internal follow-on innovation is smaller than external original innovation and that research productivity is declining with firm size. This mirrors more general findings by Bloom et al. (2020), who stress that research productivity overall has been declining sharply.

${ }^{38}$ If companies strategically precipitate their patent application, e.g. in anticipation of an increased research effort by other firms, the front-loaded effect that the estimation picks up might over-represent the change in underlying innovation. While such a behavior could move forward the measured innovation by a few years, e.g. from $t+2$ to year $t$, it is highly unlikely that this would qualitatively change the result that innovation reacts rather rapidly to changed incentives.
} 
widespread adoption. Nevertheless, the results suggest that innovation reacts very quickly to changed incentives and plausibly leads to technological progress further down the road.

\section{B. The Effect of More Detailed Climate Policies}

The analysis of the previous section has studied the magnitude and speed of the effect of an aggregate tightening in the EPS indicator. This is important to define a broad policy agenda, but the results are too coarse to be relevant for concrete policy decisions, which generally center on more precise policy instruments. To investigate how more specific policies perform in stimulating innovation, this subsection uses different EPS sub-indicators as the variables of interest in the baseline specification.

Table 3 presents the effects of the specific policies on clean innovation. In the columns 1 to 5 these are first included individually. Column 6 then assesses the impact of individual policies, controlling for them jointly. Although there has been some co-movement among individual policies, most coefficients barely change when other policies are controlled for. The results suggest that both non-market policies - such as emission limits and R\&D subsidies - as well as market policies - such as trading schemes and feed-in tariffs - made a statistically significant contribution to clean innovation. The one major exception are carbon taxes, where the effect is highly insignificant. As hinted at previously, this non-result can be explained by the very limited use of this particular policy tool during our sample. While the other policy tools analyzed here were used by 60 to 100 percent of the countries in the sample, only slightly more than 10 percent used carbon taxes in 2015 (source OECD 2018).

The absence of an effect from carbon taxes should thus not be taken at face value. Both estimates for other variables in this paper as well as results from other papers suggest that prices are actually a very powerful driver of innovation. For example, the effect of trading schemes (Table3), which also put a (though variable) price on carbon emission, is highly significant with the expected sign. The same is true for the coefficients of electricity prices, which are among the most statistically significant and robust in Table 1. Their powerful effect is in line with studies such as Popp (2002), Newell et al. (1999) Aghion et al. (2016), who all find that changes in relative prices in favor of cleaner technologies have innovation-inducing effect.

Results are also largely consistent with Johnstone et al. (2010), who focus on the effect of climate polices on innovation related to renewable energy. They too find a generally positive effect of R\&D subsidies and certificates (comparable to trading schemes) as well as an insignificant effect of tariff measures (which in their setup also include tax credits). The most notable difference is that they found an insignificant effect of feed-in tariffs, bar for solar energy ${ }^{39}$. Given the large differences in the sample, in the indicators used as well as in the estimation method (e.g. the inclusion of time-fixed effects), the similarity of the results is reassuring. Similar to Popp (2006),

\footnotetext{
${ }^{39}$ Johnstone et al 2009 explain the isolated effect of feed-in tariffs by large differences in the tariff e.g. between solar energy and wind.
} 
who investigates the effect of NOX and SO2 standards, this paper finds positive effects on innovation from emission limits.

Table 3: Effects of Individual Policies
(1)
(2)
(3)
(4)
(5)
(6)

Dependent variables: CCM Energy patent families

\begin{tabular}{|c|c|c|c|c|c|c|}
\hline L. $\ln ($ tech stock $)$ & $\begin{array}{c}0.592 * * * \\
(11.62)\end{array}$ & $\begin{array}{c}0.569 * * * \\
(14.62)\end{array}$ & $\begin{array}{c}0.655 * * * \\
(11.41)\end{array}$ & $\begin{array}{c}0.584 * * * \\
(10.89)\end{array}$ & $\begin{array}{c}0.552 * * * \\
(9.31)\end{array}$ & $\begin{array}{c}0.582 * * * \\
(12.08)\end{array}$ \\
\hline L. $\ln ($ all tech) & $\begin{array}{c}0.445^{* * *} \\
(6.47)\end{array}$ & $\begin{array}{c}0.464 * * * \\
(7.98)\end{array}$ & $\begin{array}{c}0.374 * * * \\
(6.01)\end{array}$ & $\begin{array}{c}0.398 * * * \\
(6.70)\end{array}$ & $\begin{array}{c}0.535^{* * * *} \\
(7.59)\end{array}$ & $\begin{array}{c}0.443 * * * \\
(8.29)\end{array}$ \\
\hline Co2 taxes & $\begin{array}{c}0.00595 \\
(0.27)\end{array}$ & & & & & $\begin{array}{c}-0.0255 \\
(-0.88)\end{array}$ \\
\hline trading schemes & & $\begin{array}{c}0.0377 * * \\
(2.30)\end{array}$ & & & & $\begin{array}{c}0.0367 * * * \\
(3.37)\end{array}$ \\
\hline Feed-in tariffs & & & $\begin{array}{c}0.0326 * * * \\
\quad(5.02)\end{array}$ & & & $\begin{array}{c}0.0283 * * * \\
(2.71)\end{array}$ \\
\hline emission limits & & & & $\begin{array}{c}0.0559 * * * \\
(2.63)\end{array}$ & & $\begin{array}{c}0.0385^{*} \\
(1.66)\end{array}$ \\
\hline R\&D subsidies & & & & & $\begin{array}{c}0.0592 * * * \\
(4.03)\end{array}$ & $\begin{array}{c}0.0486 * * \\
(2.39) \\
\end{array}$ \\
\hline Year FE & Yes & Yes & Yes & Yes & Yes & Yes \\
\hline Country FE & Yes & Yes & Yes & Yes & Yes & Yes \\
\hline $\mathrm{N}$ & 807 & 804 & 807 & 807 & 807 & 804 \\
\hline
\end{tabular}

Note: The table reports coefficients and t statistics from a fixed effects Poisson estimation of clean energy innovation on the environmental policy indicator and controls. The different columns differ in the specific policy instrument that is controlled for. Country- and year-fixed effects are always included. Tech stock $=$ patent stock in specific technology, all tech $=$ total patenting in all technologies. Robust standard errors. ${ }^{*} \mathrm{p}<0.10,{ }^{* *} \mathrm{p}<0.05$, $* * * \mathrm{p}<0.01$

The coefficients in Table 3 show the effects of a one-point change in the specific indicator. As different policy indicators changed to different degree over the sample period, it is not obvious to compare the relative magnitude of the coefficients. To get a better sense, Figure 5 presents the results in three alternative ways, using the coefficients from column 6 . The graph on the left shows the contribution of the individual policies, relative to a situation in which the average individual policies had stayed at the 1990 level. The graph in the middle shows the relative effects of a onestandard deviation change calculated over the entire sample. The one on the right finally shows the effect of a hypothetical move from the $10^{\text {th }}$ to the $90^{\text {th }}$ percentile in the cross-sectional distribution of 2010 .

The precise results vary slightly as different measures rely on different aspects of overall variation. E.g. as the average score of R\&D subsidies did not change very much over time, their historical contribution is smaller than other policies (left graph). The implied contribution of R\&D subsidies however increases substantially when the effect is scaled by either total variation or the crosssectional variation at the end of the sample. The exception to the overall encouraging picture are 


\section{Figure 5: Effect of Individual Policies}
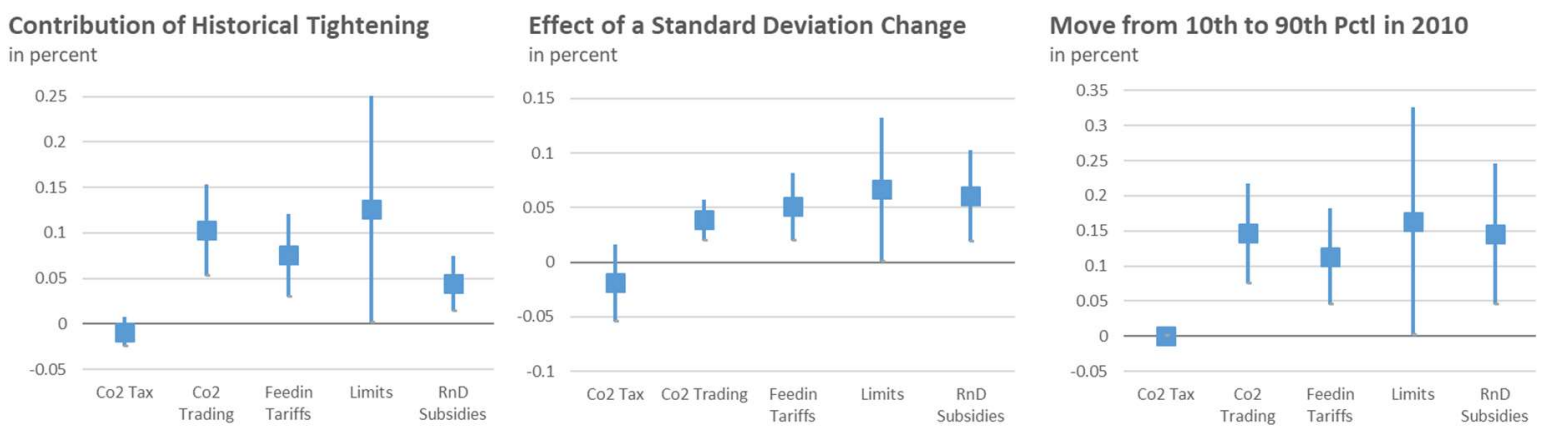

Note: Graphs respectively show effects of the historical tightening between 1990 and 2010 (left), of a onestandard deviation change over the entire sample (middle) and of a move from the $10^{\text {th }}$ to the $90^{\text {th }}$ percentile in the cross-sectional distribution in 2010 . Bands show the $90 \%$ confidence intervals.

again carbon taxes, where the variation in the sample was very small, both over time (affecting the historical contribution) as well as across countries ${ }^{40}$. While the comparison of the effects of different estimators is subject to significant caveats ${ }^{41}$, results point to historical contribution of market and non-market policy tools that are roughly in the same order of magnitude.

The fact that - with the exception of carbon taxes - different climate policy tools had independent positive effects on clean innovation is both relevant and encouraging. It lends support to the conclusions of integrated assessment models with endogenous growth that market-based policies targeting emission can strengthen incentives to invest in innovation. It however also suggests that some of the theoretically intuitive fears relative to non-market based mechanism may be unwarranted, e.g. that a static target in form of a standard provides more muted incentives to innovate than a policy that provides continuous reward for emission reduction ${ }^{42}$. Based on the historical stringency distributions of different policies, the tightening of emission limits has been among the more powerful drivers of clean innovation. While contrary to some theoretical contributions, this result is consistent with other empirical studies. Popp (2003) and Taylor (2012) for example find that the replacement of command-and-control regulation with market-based policies had a negative impact on patenting. The lower precision of or our emission-limit estimates compared to other policies could however reflect a larger heterogeneity in its effect, e.g. depending on how the emission limits are defined and adjusted.

\footnotetext{
${ }^{40}$ The estimated effect of carbon taxes going from $10^{\text {th }}$ percentile to the $90^{\text {th }}$ percentile in 2010 is zero as there is actually no difference in the score between the two points in the distribution. Both are equal to zero.

${ }^{41}$ Comparing movements on the stringency-distribution of individual policy indicators makes the estimated effects independent of its magnitude, as e.g. doubling the indicator would reduce by half the coefficient. However, the estimated effects still crucially depend on how much the use of a policy tool has differed over to the two dimensions of the sample. E.g. while we can compare the effect of a move from the $10^{\text {th }}$ to the $90^{\text {th }}$ percentile, we cannot assess how significant these moves are for the different policies, e.g. in terms of emissions or carbon-tax equivalent USD. Addressing these shortcomings does however not lie within the scope of this paper.

${ }^{42}$ See e.g. Milliman \& Prince (1989) for a conceptual comparison between command-and-control policies and different market-based policies; or Fischer et al. (2003) for an analysis more focused on market-based instruments. Jaffe \& Stavins (1995), investigate the use of thermal insulation technologies and provide another useful framework as well as some empirical evidence that, in the specific field investigated, standards had a smaller effect than market-based policies.
} 
From a policy point of view, the positive and individually significant effects of different policy tools is encouraging, as it points to some substitutability among them as far as innovation is concerned. This is good news for policy makers as it suggests that climate policy tools should be used and potentially combined focusing on their political feasibility and their expected effect on carbon emissions.

\section{Clean, Grey, Dirty and Total Electricity Innovation}

The last part of this section expands the analysis from an exclusive focus on clean technologies. This is meant to investigate the effects on total innovation in each technological field -independent of whether it can be considered clean. The underlying question is whether an increase in clean innovation is offset by a decline in other types of innovation.

For the comparison of different types, the focus is narrowed to technologies related to electricity. The immediate reason for this choice is that it allows the analysis to rely on the technological classification from Dechezleprêtre et al (2017), which distinguishes electricity technologies of clean, grey ${ }^{43}$ and dirty types. Such a focus has the additional advantage of narrowing the identification, as it reduces the scope for cross-technology substitution, with a very limited cost in terms of representativeness. Clean electricity innovation identified by Dechezleprêtre et al. (2017) is highly correlated with the clean energy innovation identified by the OECD: the average countryspecific correlation over time is $95 \%$. In addition, and as mentioned already earlier, electricity is also a major part of total energy, both in terms of emission as well as innovation. It thus seems plausible that results found for electricity are applicable to the broader energy category.

Table 4 reports the results for the different types of technology. Different to the baseline specification in Table 1, this model controls not only for the available knowledge stocks of the specific technology, but also for the stock of electricity technology overall. In addition, columns (1) to (3) impose a coefficient of 1 on total patenting in electricity innovation, the sum of clean, grey, and dirty. The interpretation of the coefficient of interest is thus similar to the effects on the relevant shares; it is the elasticity of the particular type of innovation controlling for electricity innovation overall ${ }^{44}$. A final difference is the inclusion of oil and gas reserves. These were insignificant in Table 1 but affect clean and dirty electricity innovation very differently; the effect of oil and gas reserves is negative and statistically significant in column (1) of Table 4, but positive though insignificant in column (3).

\footnotetext{
${ }^{43}$ Grey technologies as identified by Dechezleprêtre et al (2017) tend to improve the pollution efficiency of "dirty" technologies. Examples include technologies that mitigate $\mathrm{Co} 2$ emissions, use the heat from fuel or waste incineration or produce fuels from non-fossil sources.

${ }^{44}$ The specification is not identical to a regression of actual shares, as the relative weight of different countries is not identical. In the estimation used for Table 4, bigger countries in terms of innovation tend to get bigger weights, as they are responsible for a bigger share of the variance of the residual. Using shares as the dependent variable would a priori attribute identical weights to all countries. In fact, due to the law of large numbers, shares might actually be more volatile in smaller countries for factors unrelated to the model. The estimation of Table 4 is thus preferable to a regression of shares for economical as well as statistical reasons.
} 
Table 4: Relative and Absolute Electricity Innovation

(1) (2) (3)

Clean grey dirty

(4)

total

Dependent variables: Patent families related to different types of electricity

\begin{tabular}{lcccc} 
L.EPS & $0.0625 * * *$ & $0.150 * * *$ & $-0.0402 * *$ & $0.201 * * *$ \\
& $(2.64)$ & $(3.39)$ & $(-2.14)$ & $(3.49)$ \\
L.ln(all tech) & 0.0572 & $-0.352^{* * *}$ & $0.0520^{* *}$ & $0.416^{* * *}$ \\
& $(0.58)$ & $(-3.40)$ & $(2.28)$ & $(4.07)$ \\
L.ln(oil \& gas reserves) & $-0.103 * *$ & -0.0836 & 0.0361 & -0.0419 \\
& $(-2.03)$ & $(-1.37)$ & $(1.33)$ & $(-0.31)$ \\
L.ln(all electr stock) & -0.182 & 0.171 & -0.189 & $0.638^{* * *}$ \\
& $(-0.95)$ & $(0.80)$ & $(-0.47)$ & $(4.14)$ \\
L.ln(spec electr stock) & 0.125 & $0.513 * * *$ & 0.131 & \\
& $(0.92)$ & $(6.67)$ & $(0.32)$ & \\
$\ln ($ all electr) & 1.00 & 1.00 & 1.00 & \\
& () & () & () & \\
\hline Year FE & Yes & Yes & Yes & Yes \\
Country FE & Yes & Yes & Yes & Yes \\
N & 743 & 743 & 743 & 743 \\
\hline
\end{tabular}

Note: The table reports coefficients and t statistics from a fixed effects Poisson estimation of different types of electricity innovation on the environmental policy indicator and controls, including total patenting $(\ln ($ all tech)), the existing knowledge stocks in the specific ( $\ln ($ spec electr stock)) and overall ( $\ln ($ all electr stock)) electricity technology and proven oil and gas reserves $(\ln ($ oil $\&$ gas reserves)). The coefficient on overall electricity innovation $\left(\ln (\right.$ all electr) $)$ is constrained at 1 . Robust standard errors. ${ }^{*} \mathrm{p}<0.10, * * \mathrm{p}<0.05,{ }^{* * *} \mathrm{p}<0.01$

The results suggest that environmental policies have increased the shares of clean - and even more so grey - innovation (column 1 and 2). The coefficients of the different types of technology are statistically significant, at least at the 5\% level. The magnitude of grey innovation stands out and warrants some discussion. It is not implausible that grey technologies are less radically new and may thus be closer to commercialization. This could make it particularly attractive to direct research efforts in this direction. However, the large coefficients for grey innovation also needs to be seen in light of the much lower initial level (Figure 6). While the proportional increase in grey innovation may be large, its overall impact on electricity innovation can still be moderate. The need for a cautious interpretation of the effect on grey innovation is further underscored by the reduced robustness of this particular coefficient, as illustrated in the appendix.

Column 4 illustrates the effect on total electricity innovation. The effect of environmental policies is again strong and positive. The relative decrease in dirty innovation (column 3 ) was thus more than offset by increased innovation in the other categories. This suggests that a complete crowding out, as assumed by some integrated assessment models with endogenous growth (e.g. Nordhaus, 2002), may be too pessimistic ${ }^{45}$. Whether this is good or bad news depends on the point of view and what the actually feasible alternative is. From the point of view of the climate, a rapid shift in

45 This result is partially in line with Popp \& Newell (2012) who - based on micro data - find that clean innovation is partly crowding out other $\mathrm{R} \& \mathrm{D}$ in the sectors of alternative energy, not however in automotive manufacturing. 
research from dirty to clean innovation could accelerate the energy transition. A collapse in dirty innovation could thus be part of the solution, to the extent that it increases the prices and reduces the consumption of dirty energy or even energy overall. From a macro-economic point of view, such a scenario would be disruptive. It could also reduce the political feasibility of an ambitious climate agenda. Instead, if clean innovational is additional, a positive effect on growth could allow an energy transition that is growth neutral or potentially even growth positive (see IMF, 2020 for the discussion of a plausible growth impact over different horizons of an ambitious climate agenda).
Figure 6: Environmental Policy, Innovation, and Oil Prices

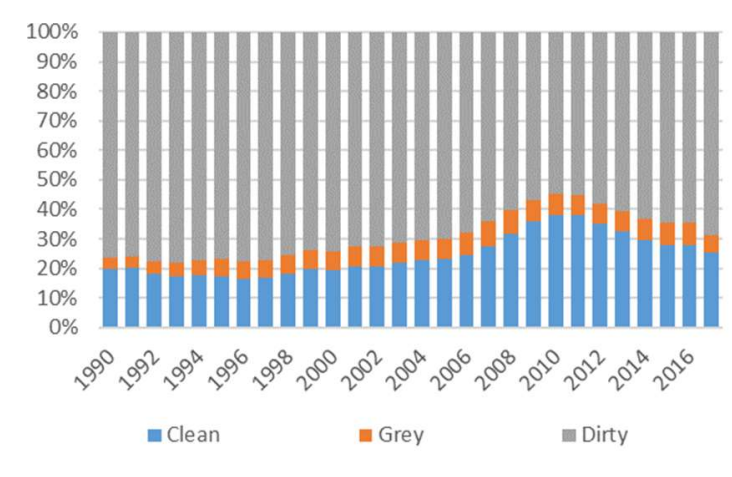

Sources: PATSTAT, FRED, OECD, author's calculation

\section{SENSITIVITY ANALYSIS}

This section discusses key robustness checks. The corresponding tables are reported in the Appendix.

\section{Aggregate Effect of Environmental Policies}

Given that Table 1 already includes various different specifications, the robustness tests here focus on different ways of measuring innovation, as well as dropping key innovator countries from the sample.

The tables A1 and A2 explore how the overall effect on clean energy innovation changes if instead of using patent families, the innovation count is respectively based on all patents or only patent families with applications in at least two patent offices (here called international patent families). The top innovating countries hardly change with the measure, but their relative sizes do. Going from patent families to all applications increases the innovation score mostly for the US and Japan. Going from all families to only international patent families significantly reduces the importance of China.

Results are qualitatively highly robust. The coefficients stay statistically significant except in very few cases, where the inclusion of additional controls cuts the sample by almost half. The 
coefficients remain of a similar magnitude, though decline somewhat, particularly if international patent families are used ${ }^{46}$.

Next, the paper explores how the baseline effect changes if key innovator countries are dropped from the sample. Given that global innovation is highly concentrated in a handful of countries, there is a risk that one of them could have a dominant effect on the main results. As shown in Table A3, this is not the case. Dropping any of the key innovators does not materially change the results. The coefficient increases slightly when Korea is dropped and decreases somewhat when the same is done for Japan; the statistical significance however remains unaffected.

\section{The Dynamics of the Effect}

The results related to the dynamic effects shown in Table 2 only use the baseline specification of column (1) in Table 1. The related robustness checks thus focus on alternative specifications that include additional controls, keeping the dependent variable the same. The Tables A4 and A5 replicate the dynamic analysis, respectively controlling also for oil and gas reserves and electricity prices, the two variables that proved relevant in some specifications and which have a still comparable data coverage. The inclusion of oil and gas reserves, though highly statistically significant with the expected sign, weakens the results very slightly. Electricity prices on the other hand, though themselves statistically insignificant, tend to reinforce the results quite substantially, particularly two to four years after the policy change. This is to a large extent due to the change in sample, as electricity prices are not available for most emerging markets in the sample.

\section{Effects of Specific Policies}

Similarly, the robustness of the effects of the individual policies is explored relative to additional controls. The Tables A6 and A7 report the effects of the individual policies controlling again for oil and gas reserves as well as electricity prices at the household level. While the former is insignificant and the latter reduces the sample by about 20 percent, neither changes much the results. With the exception of carbon prices, the coefficients of the policy variables generally remain statistically significant and very similar in magnitude.

\section{$\underline{\text { Robustness - Different Types of Electricity Innovation }}$}

Finally, Tables A8 and A9 explore the robustness of the results for the different types of electricity innovation. The specifications in Table A8 do not restrict the coefficient on total electricity innovation to 1 . The unconstrained estimates are close to 1 for dirty and clean electricity innovation, but significantly larger for grey innovation. The additional coefficient to be estimated slightly reduces the precision. Overall, however, results are very similar. Further, Table A9 first removes oil and gas reserves from the estimation (columns 1 to 3 ) before also including electricity

\footnotetext{
${ }^{46}$ Why this is the case is not a priori obvious. One plausible option is that patenting reacts more strongly to local incentives in some countries than others. E.g. European innovators, which tend to be more likely to patent in more than one country (given a relatively low cost), may react as much to continent-wide incentives than local ones, which could reduce the estimated impact.
} 
prices (columns 4 to 6). As hinted at earlier, the coefficient on grey innovation becomes insignificant if oil and gas reserves are omitted. When the inclusion of electricity prices reduces the sample by about $20 \%$, the coefficient on dirty innovation becomes insignificant, while the one on clean and grey innovation remain very close to the ones in Table 4 .

\section{CONCLUSION}

The paper has looked at the effects on clean energy innovation of the tightening in environmental policies since the early 1990s. Results point to a statistically significant and economically important contribution, roughly equivalent to a permanent 70 USD increase in the price of a barrel of crude oil. The evidence further suggests that the effects materialize quickly and are roughly comparable for market- and non-market-based policies. A closer look at the electricity sector suggests that environmental policies have contributed to a shift away from dirty towards clean and grey innovation, with a net positive effect on electricity innovation overall. The results thus suggest that environmental policies not only change the composition but also the extent of innovation.

From a policy point of view, the paper thus emphasizes both the necessity for additional policy efforts as well as their political feasibility. The finding that various environmental policy tools can induce additional innovation in clean technologies is encouraging. Not only does it mean that climate policies can be used and potentially combined depending on political preferences and their expected effects on carbon emissions. It also means that the endogenous reaction of innovation reduces the macro-economic costs of an ambitious climate agenda by (i) helping clean technologies to become viable, cost-effective alternatives more quickly and (ii) increasing technological progress overall. However, the fact that the induced innovation largely complements rather than replaces innovation in traditional technologies may actually slow the energy transition if continued innovation in dirty technologies postpones their replacement by cleaner alternatives.

Further research is however needed to compare the effectiveness and costs of different policy tools, also considering greenhouse gas emission, and determine which combinations would most decisively shift energy-sector innovation toward clean options. 


\section{APPENDIX}

\section{Table A1: Aggregate Effect on All Clean Patent Applications}

(1)
(2)
(3)

(4)
(5)

(6)

Dependent variables: All CCM Energy patent applications

\begin{tabular}{|c|c|c|c|c|c|c|}
\hline L.EPS & $\begin{array}{c}0.116^{* * *} \\
(4.21)\end{array}$ & $\begin{array}{c}0.134 * * * \\
(4.53)\end{array}$ & $\begin{array}{c}0.112 * * * \\
(4.36)\end{array}$ & $\begin{array}{c}0.122 * * * \\
(4.17)\end{array}$ & $\begin{array}{c}0.0981 * * * \\
(4.43)\end{array}$ & $\begin{array}{c}0.106 * * * \\
(3.77)\end{array}$ \\
\hline L.ln(tech stock) & $\begin{array}{c}0.589 * * * \\
(15.45)\end{array}$ & $\begin{array}{c}0.646 * * * \\
(15.15)\end{array}$ & $\begin{array}{c}0.550 * * * \\
(14.58)\end{array}$ & $\begin{array}{c}0.605 * * * \\
(9.73)\end{array}$ & $\begin{array}{c}0.519 * * * \\
(19.86)\end{array}$ & $\begin{array}{c}0.431 * * * \\
(6.97)\end{array}$ \\
\hline L. $\ln ($ all tech $)$ & $\begin{array}{c}0.384 * * * \\
(10.56)\end{array}$ & $\begin{array}{c}0.358 * * * \\
(6.91)\end{array}$ & $\begin{array}{c}0.421 * * * \\
(5.05)\end{array}$ & $\begin{array}{c}0.445 * * * \\
(4.14)\end{array}$ & $\begin{array}{c}0.169 * * \\
(2.44)\end{array}$ & $\begin{array}{l}0.276 \\
(1.62)\end{array}$ \\
\hline L.ln(oil \& gas reserves in bb) & & $\begin{array}{c}-0.0641 \\
(-1.10)\end{array}$ & & $\begin{array}{c}-0.0725 \\
(-1.00)\end{array}$ & & $\begin{array}{c}-0.00664 \\
(-0.07)\end{array}$ \\
\hline L. Electr. price for HH (USD) & & & $\begin{array}{c}0.0996 \\
(1.19)\end{array}$ & $\begin{array}{c}0.0350 \\
(0.37)\end{array}$ & & $\begin{array}{l}0.153 \\
(1.45)\end{array}$ \\
\hline L.ETCR electricity & & & & & $\begin{array}{c}-0.0772 * * \\
(-2.36)\end{array}$ & $\begin{array}{c}-0.0713^{*} \\
(-1.87)\end{array}$ \\
\hline L. Labor market reg. (EFW) & & & & & $\begin{array}{c}0.000600 \\
(0.03)\end{array}$ & $\begin{array}{c}-0.0153 \\
(-0.52) \\
\end{array}$ \\
\hline $\mathrm{N}$ & 781 & 743 & 608 & 579 & 424 & 352 \\
\hline
\end{tabular}

Table A2: Aggregate Effect on Clean International Patent Families Only

Dependent variables: Only international CCM Energy patent families

\begin{tabular}{|c|c|c|c|c|c|c|}
\hline L.EPS & $\begin{array}{c}0.0643 * * \\
(2.41)\end{array}$ & $\begin{array}{c}0.0992 * * * \\
(4.61)\end{array}$ & $\begin{array}{c}0.0693 * * * \\
(2.65)\end{array}$ & $\begin{array}{c}0.0982 * * * \\
(4.71)\end{array}$ & $\begin{array}{c}0.0447 * \\
(1.71)\end{array}$ & $\begin{array}{c}0.0517 * \\
(1.79)\end{array}$ \\
\hline L. $\ln ($ tech stock $)$ & $\begin{array}{c}0.594 * * * \\
(8.58)\end{array}$ & $\begin{array}{c}0.554 * * * \\
(5.83)\end{array}$ & $\begin{array}{c}0.632 * * * \\
(6.89)\end{array}$ & $\begin{array}{c}0.616^{* * * *} \\
(4.93)\end{array}$ & $\begin{array}{c}0.508 * * * \\
(8.81)\end{array}$ & $\begin{array}{c}0.511 * * * \\
(4.23)\end{array}$ \\
\hline L. $\ln ($ all tech $)$ & $\begin{array}{c}0.288 * * * \\
(4.74)\end{array}$ & $\begin{array}{c}0.338 * * * \\
(4.56)\end{array}$ & $\begin{array}{c}0.282^{*} \\
(1.93)\end{array}$ & $\begin{array}{c}0.240 * * \\
(2.15)\end{array}$ & $\begin{array}{c}0.266^{* * * *} \\
(3.00)\end{array}$ & $\begin{array}{c}0.242^{*} \\
(1.83)\end{array}$ \\
\hline L.ln(oil \& gas reserves, bb) & & $\begin{array}{c}-0.135 * * * \\
(-4.67)\end{array}$ & & $\begin{array}{c}-0.132 * * * \\
(-3.88)\end{array}$ & & $\begin{array}{c}-0.138 * * * \\
(-3.14)\end{array}$ \\
\hline L.In(electr. price HH, USD) & & & $\begin{array}{c}0.0861 \\
(1.06)\end{array}$ & $\begin{array}{c}0.0190 \\
(0.24)\end{array}$ & & $\begin{array}{c}0.196^{* *} \\
(1.99)\end{array}$ \\
\hline L.ETCR electricity & & & & & $\begin{array}{c}-0.0374 \\
(-1.46)\end{array}$ & $\begin{array}{c}-0.0258 \\
(-0.71)\end{array}$ \\
\hline L. Labor market reg. (EFW) & & & & & $\begin{array}{c}-0.0339 \\
(-1.32)\end{array}$ & $\begin{array}{c}-0.0702 * \\
(-1.94)\end{array}$ \\
\hline $\mathrm{N}$ & 781 & 743 & 608 & 579 & 424 & 352 \\
\hline
\end{tabular}

Note: The tables report coefficients and robust standard errors from a fixed effects Poisson estimation of clean energy innovation on an environmental policy indicator and controls. $* \mathrm{p}<0.10, * * \mathrm{p}<0.05, * * * \mathrm{p}<0.01$ 
A3: Aggregate Effect when dropping Key Innovator Countries

(1) (2) (3) (4)

(5)

Dependent variables: CCM Energy patent families

\begin{tabular}{lccccc} 
Country dropped & CHN & DEU & JPN & KOR & USA \\
L.EPS & $0.191^{* * *}$ & $0.190^{* * *}$ & $0.129^{* * *}$ & $0.227^{* * *}$ & $0.168^{* * *}$ \\
& $(6.09)$ & $(4.68)$ & $(3.95)$ & $(5.60)$ & $(4.16)$ \\
L.ln(tech stock) & $0.549^{* * *}$ & $0.600^{* * *}$ & $0.555^{* * *}$ & $0.758^{* * *}$ & $0.617^{* * *}$ \\
& $(9.17)$ & $(10.02)$ & $(9.95)$ & $(7.93)$ & $(9.53)$ \\
L.ln(all tech) & $0.514^{* * *}$ & $0.415 * * *$ & $0.428^{* * *}$ & $0.270^{* * *}$ & $0.392^{* * *}$ \\
& $(4.28)$ & $(6.97)$ & $(7.89)$ & $(2.67)$ & $(6.30)$ \\
\hline $\mathrm{N}$ & 755 & 755 & 755 & 755 & 755 \\
\hline
\end{tabular}


Table A4: The Dynamics of the Effect, including Oil \& Gas Reserves

(3)

(4)

Dependent variables: Log-Difference in CCM Energy patent families between $\boldsymbol{t}+\mathbf{1}$ and $\boldsymbol{t}+\boldsymbol{j}$

\begin{tabular}{lccccc} 
& $\boldsymbol{t}$ & $\boldsymbol{t}+\mathbf{1}$ & $\boldsymbol{t}+\mathbf{2}$ & $\boldsymbol{t}+\mathbf{3}$ & $\boldsymbol{t}+\mathbf{4}$ \\
EPS & $0.101^{* *}$ & $0.115^{*}$ & 0.135 & 0.110 & 0.113 \\
& $(2.58)$ & $(1.92)$ & $(1.63)$ & $(0.93)$ & $(0.97)$ \\
L.In(tech stock) & $-0.221^{* * *}$ & $-0.385^{* * *}$ & $-0.529 * * *$ & $-0.622^{* * *}$ & $-0.688^{* * *}$ \\
& $(-4.03)$ & $(-4.11)$ & $(-4.26)$ & $(-4.94)$ & $(-5.15)$ \\
$\ln ($ oil price) & $0.217 * * *$ & $0.365^{* * *}$ & $0.331 * * *$ & $0.292^{* * *}$ & 0.147 \\
& $(3.73)$ & $(4.05)$ & $(3.12)$ & $(2.83)$ & $(1.24)$ \\
$\Delta$ L.ln(all tech) & $0.542^{* * *}$ & $0.428^{* *}$ & $0.377^{*}$ & $0.388^{*}$ & $0.392 * * *$ \\
& $(4.29)$ & $(2.47)$ & $(1.77)$ & $(1.95)$ & $(2.96)$ \\
$\ln ($ oil \& gas reserves, bb) & -0.00209 & -0.0401 & -0.0891 & -0.110 & -0.169 \\
& $(-0.05)$ & $(-0.64)$ & $(-1.09)$ & $(-1.11)$ & $(-1.56)$ \\
\hline $\mathrm{N}$ & 632 & 601 & 570 & 539 & 508 \\
$\mathrm{r} 2$ & 0.290 & 0.288 & 0.336 & 0.378 & 0.410 \\
\hline
\end{tabular}

Table A5: The Dynamics of the Effect, including Electricity Prices

Dependent variables: Log-Difference in CCM Energy patent families between $\boldsymbol{t}+\mathbf{1}$ and $\boldsymbol{t}+\boldsymbol{j}$

\begin{tabular}{|c|c|c|c|c|c|}
\hline & $\boldsymbol{t}$ & $t+1$ & $t+2$ & $t+3$ & $t+4$ \\
\hline \multirow{2}{*}{ EPS } & $0.117 * *$ & $0.200 * * *$ & $0.237 * * *$ & $0.266 * *$ & $0.232 * *$ \\
\hline & $(2.74)$ & $(3.55)$ & $(3.44)$ & $(2.69)$ & $(2.39)$ \\
\hline \multirow[t]{2}{*}{ L. $\ln ($ tech stock $)$} & $-0.186 * * *$ & $-0.305 * * *$ & $-0.410 * * *$ & $-0.516 * * *$ & $-0.616 * * *$ \\
\hline & $(-3.55)$ & $(-3.44)$ & $(-3.23)$ & $(-3.43)$ & $(-3.97)$ \\
\hline \multirow[t]{2}{*}{$\ln ($ oil price $)$} & $0.229 * * *$ & $0.388 * * *$ & $0.353 * * *$ & $0.328 * * *$ & 0.186 \\
\hline & $(3.14)$ & $(3.61)$ & $(2.88)$ & $(3.27)$ & (1.49) \\
\hline \multirow[t]{2}{*}{$\Delta \ln ($ all tech $)$} & $0.624 * * *$ & $0.552 * * *$ & $0.512 * * *$ & $0.473 * * *$ & $0.389 * * *$ \\
\hline & $(8.88)$ & $(6.03)$ & $(4.95)$ & $(4.57)$ & $(4.11)$ \\
\hline \multirow[t]{2}{*}{$\ln ($ electr. price HH, USD) } & -0.0364 & -0.0461 & -0.00958 & 0.0163 & 0.0549 \\
\hline & $(-0.55)$ & $(-0.41)$ & $(-0.07)$ & $(0.13)$ & $(0.46)$ \\
\hline $\mathrm{N}$ & 500 & 473 & 447 & 421 & 395 \\
\hline $\mathrm{r} 2$ & 0.324 & 0.339 & 0.377 & 0.461 & 0.471 \\
\hline
\end{tabular}

Note: The tables report coefficients and $t$ statistics from a fixed effects panel regression of the log-change in clean energy innovation between $t+1$ and $t+j$ on an environmental policy indicators and controls. $\Delta \ln ($ all tech) refers to the log difference of total patenting over the same period. Country-fixed effects, a trend, the values of the EPS between $t$ and $t+j$, as well as three lags of both the EPS indicator and the growth of innovation are included but not reported for brevity. EPS = environmental policy stringency; tech stock = patent stock in specific technology. Robust standard errors. ${ }^{*} \mathrm{p}<0.10,{ }^{* *} \mathrm{p}<0.05, * * * \mathrm{p}<0.01$ 


\section{Table A6: Effect of Individual Policies, including Oil \& Gas Reserves}

(1)
(2)

Dependent variables: CCM Energy patent families

Table A7: Effect of Individual Policies, including Electricity Prices

Dependent variables: All CCM Energy patent applications

\begin{tabular}{|c|c|c|c|c|c|c|}
\hline L. $\ln$ (tech stock) & $\begin{array}{c}0.526 * * * \\
(11.79)\end{array}$ & $\begin{array}{c}0.514 * * * \\
(12.57)\end{array}$ & $\begin{array}{c}0.581 * * * \\
(13.12)\end{array}$ & $\begin{array}{c}0.505 * * * \\
(12.69)\end{array}$ & $\begin{array}{c}0.490 * * * \\
(8.19)\end{array}$ & $\begin{array}{c}0.536 * * * \\
(10.83)\end{array}$ \\
\hline L.ln(all tech) & $\begin{array}{c}0.598 * * * \\
(5.14)\end{array}$ & $\begin{array}{c}0.587 * * * \\
(5.16)\end{array}$ & $\begin{array}{c}0.553 * * * \\
(5.71)\end{array}$ & $\begin{array}{c}0.512 * * * \\
(4.56)\end{array}$ & $\begin{array}{c}0.684 * * * \\
(5.14)\end{array}$ & $\begin{array}{c}0.526^{* * *} * \\
(5.07)\end{array}$ \\
\hline L.In(electr. price HH) & $\begin{array}{c}0.283^{* *} \\
(2.17)\end{array}$ & $\begin{array}{c}0.219 * \\
(1.76)\end{array}$ & $\begin{array}{c}0.365 * * * \\
(3.01)\end{array}$ & $\begin{array}{c}0.221^{* *} \\
(2.26)\end{array}$ & $\begin{array}{c}0.299 * * \\
(2.28)\end{array}$ & $\begin{array}{c}0.265^{* *} \\
(2.56)\end{array}$ \\
\hline Co2 taxes & $\begin{array}{c}0.0220 \\
(0.53)\end{array}$ & & & & & $\begin{array}{c}-0.0328 \\
(-1.03)\end{array}$ \\
\hline trading schemes & & $\begin{array}{c}0.0267 * * \\
(2.34)\end{array}$ & & & & $\begin{array}{c}0.0295 * * * \\
\quad(3.11)\end{array}$ \\
\hline Feed-in tariffs & & & $\begin{array}{c}0.0409 * * * \\
\quad(4.10)\end{array}$ & & & $\begin{array}{c}0.0407 * * * \\
\quad(4.03)\end{array}$ \\
\hline emission limits & & & & $\begin{array}{c}0.0632 * * \\
(2.24)\end{array}$ & & $\begin{array}{c}0.0435 \\
(1.37)\end{array}$ \\
\hline R\&D subsidies & & & & & $\begin{array}{c}0.0478 * * * \\
(2.91)\end{array}$ & $\begin{array}{c}0.0227 \\
(1.59) \\
\end{array}$ \\
\hline $\mathrm{N}$ & 608 & 608 & 608 & 608 & 608 & 608 \\
\hline
\end{tabular}

Note: The tables report coefficients and $t$ statistics from a fixed effects Poisson estimation of clean energy innovation on different environmental policy indicator and controls. Country- and year-fixed effects are always included. Tech stock $=$ patent stock in specific technology, all tech $=$ total patenting in all technologies. Robust standard errors. ${ }^{*} \mathrm{p}<0.10,{ }^{* *}$ $\mathrm{p}<0.05, * * * \mathrm{p}<0.01$ 
Table A8: Relative Electricity Innovation with Unconstrained Effects of Total Electricity Innovation

(1)

clean
(2)

grey
(3)

dirty

Dependent variables: Patent families related to different types of electricity technologies

\begin{tabular}{lccc} 
L.EPS & $0.0537 *$ & $0.0911^{*}$ & $-0.0372^{*}$ \\
& $(1.86)$ & $(1.93)$ & $(-1.83)$ \\
L.ln(all tech) & 0.0177 & $-0.484^{* * *}$ & $0.0634^{* * *}$ \\
& $(0.18)$ & $(-3.99)$ & $(2.90)$ \\
L.ln(spec electr stock) & -0.0508 & $0.575^{* * *}$ & 0.0261 \\
& $(-0.68)$ & $(8.56)$ & $(0.09)$ \\
L.ln(all electr stock) & -0.0343 & -0.148 & -0.0807 \\
& $(-0.19)$ & $(-0.90)$ & $(-0.27)$ \\
L.ln(oil \& gas reserves) & $-0.131^{* *}$ & $-0.0812^{* *}$ & 0.0394 \\
& $(-2.39)$ & $(-1.99)$ & $(1.50)$ \\
$\ln ($ all electr) & $1.092^{* * *}$ & $1.361^{* * *}$ & $0.982^{* * *}$ \\
& $0.0537^{*}$ & $0.0911^{*}$ & $-0.0372^{*}$ \\
\hline $\mathrm{N}$ & 743 & 743 & 743 \\
\hline
\end{tabular}

Table A9: Relative Electricity with Fewer or Additional Controls
(1)
(2)
(3)
(4)
(5)
clean grey
dirty
clean
grey
(6)
dirty

Dependent variables: Patent families related to different types of electricity technologies

\begin{tabular}{llll|lll} 
L.EPS & $0.0487^{* * *}$ & 0.0786 & $-0.0393^{* * *}$ & 0.0304 & $0.156^{* * *}$ & -0.00441 \\
& $(3.00)$ & $(1.28)$ & $(-3.13)$ & $(1.39)$ & $(6.58)$ & $(-0.46)$ \\
L.In(all tech) & -0.0880 & $-0.254^{* * *}$ & $0.105^{* * *}$ & 0.0298 & -0.120 & $0.0686^{* * *}$ \\
& $(-1.33)$ & $(-2.90)$ & $(4.02)$ & $(0.40)$ & $(-1.48)$ & $(4.08)$ \\
L.In(spec stock) & $0.443^{* * *}$ & $0.508^{* * *}$ & $0.453^{*}$ & $0.308^{* *}$ & $0.718^{* * *}$ & 0.473 \\
& $(3.48)$ & $(8.39)$ & $(1.81)$ & $(2.24)$ & $(8.10)$ & $(1.36)$ \\
L.ln(all electr stock) & $-0.382^{* *}$ & 0.0161 & $-0.561^{* *}$ & $-0.474^{* * *}$ & -0.239 & -0.473 \\
& $(-2.44)$ & $(0.11)$ & $(-2.45)$ & $(-2.60)$ & $(-1.14)$ & $(-1.39)$ \\
L.In(oil \& gas reser.) & & & & $-0.0745^{*}$ & -0.0656 & 0.0199 \\
& & & & $(-1.66)$ & $(-1.35)$ & $(1.42)$ \\
L.ln(electr. price HH) & & & & $-0.110^{*}$ & $0.329^{* * *}$ & 0.0294 \\
$\ln ($ all electr) & 1.00 & 1.00 & 1.00 & $(-1.77)$ & $(4.57)$ & $(1.19)$ \\
& ( & () & () & 0 & 1.00 & 1.00 \\
\hline $\mathrm{N}$ & 781 & 781 & 781 & 579 & 0 & 0 \\
\hline
\end{tabular}

Note: Besides the overall EPS indicator, the regression controls for total patenting, the existing knowledge stocks in the specific and overall electricity technology and proven oil and gas reserves. The coefficient on overall electricity innovation is constrained at 1 . Robust standard errors in parentheses. ${ }^{*} \mathrm{p}<0.10, * * \mathrm{p}<0.05, * * * \mathrm{p}<0.01$ 


\section{REFERENCES}

Acemoglu, Daron \& Philippe Aghion \& Leonardo Bursztyn \& David Hemous, 2012. "The Environment and Directed Technical Change," American Economic Review, American Economic Association, vol. 102(1), pages 131-166, February.

Acemoglu, Daron \& Ufuk Akcigit \& Douglas Hanley \& William Kerr, 2016. "Transition to Clean Technology," Journal of Political Economy, University of Chicago Press, vol. 124(1), pages 52-104.

Acemoglu, Daron \& David Hemous \& Lint Barrage \& Philippe Aghion, 2019. "Climate Change, Directed Innovation, and Energy Transition: The Long-run Consequences of the Shale Gas Revolution," 2019 Meeting Papers 1302, Society for Economic Dynamics.

Akcigit, Ufuk \& William R. Kerr, 2018."Growth through Heterogeneous Innovations," Journal of Political Economy, University of Chicago Press, vol. 126(4), pages 1374-1443.

Aghion, Philippe \& Antoine Dechezleprêtre \& David Hémous \& Ralf Martin \& John Van Reenen, 2016. "Carbon Taxes, Path Dependency, and Directed Technical Change: Evidence from the Auto Industry," Journal of Political Economy, University of Chicago Press, vol. 124(1), pages 1-51.

Auerbach, Alan J., and Yuriy Gorodnichenko, 2013, "Output Spillovers from Fiscal Policy," American Economic Review: Papers and Proceedings, vol. 103(3), pp. 141-146.

Bloom, Nicholas \& Charles I. Jones \& John Van Reenen \& Michael Webb, 2020. "Are Ideas Getting Harder to Find?," American Economic Review, American Economic Association, vol. 110(4), pages 1104-1144, April.

Barret, Philip, "Can International Technological Diffusion Substitute for Coordinated Global Policies to Mitigate Climate Change?", IMF Working Paper, Nr. 21/173

Bosetti, Valentina, Carlo Carraro, Emanuele Massetti, and Massimo Tavoni. 2008. "InternationalEnergy R\&D Spillovers and the Economics of Greenhouse Gas Atmospheric Stabilization.” Energy Economics 30(6): 2912-29.

Botta, Enrico \& Tomasz Koźluk, 2014. "Measuring Environmental Policy Stringency in OECD Countries: A Composite Index Approach," OECD Economics Department Working Papers 1177, OECD Publishing.

Bouis, Romain \& Duval, Romain \& Eugster, Johannes, 2020. "How fast does product market reform pay off? New evidence from non-manufacturing industry deregulation in advanced economies," Journal of Comparative Economics, Elsevier, vol. 48(1), pages 198-217.

Bruckner T., I. A. Bashmakov, Y. Mulugetta, H. Chum, A. de la Vega Navarro, J. Edmonds, A. Faaij, B. Fungtammasan, A. Garg, E. Hertwich, D. Honnery, D. Infield, M. Kainuma, S. Khennas, S. Kim, H. B. Nimir, K. Riahi, N. Strachan, R. Wiser, and X. Zhang, 2014: Energy Systems. In: Climate Change 2014: Mitigation of Climate Change. Contribution of Working Group III to the Fifth Assessment Report of the Intergovernmental Panel on Climate Change 
Dechezlepretre, Antoine, Ralf Martin, Myra Mohnen, 2017. "Knowledge Spillovers from clean and dirty technologies," GRI Working Papers 135, Grantham Research Institute on Climate Change and the Environment.

Fischer, Carolyn \& Parry, Ian W. H. \& Pizer, William A., 2003. "Instrument choice for environmental protection when technological innovation is endogenous," Journal of Environmental Economics and Management, Elsevier, vol. 45(3), pages 523-545, May.

Fried, Stephie, 2018. "Climate Policy and Innovation: A Quantitative Macroeconomic Analysis," American Economic Journal: Macroeconomics, American Economic Association, vol. 10(1), pages 90-118, January.

Furceri, Davide \& Swarnali A Hannan \& Jonathan David Ostry \& Andrew K. Rose, 2019. "Macroeconomic Consequences of Tariffs," IMF Working Papers 2019/009, International Monetary Fund.

Haščič, Ivan \& Mauro Migotto, 2015. "Measuring environmental innovation using patent data," OECD Environment Working Papers 89, OECD Publishing.

Hassler, John, Per Krusell, Conny Olovsson, and Michael Reiter. 2020. "On the Effectiveness of Climate Policy

IMF, "Mitigating Climate Change", Chapter 3 in October 2020 World Economic Outlook 2020

Jaffe, Adam B. \& Stavins Robert N., 1995."Dynamic Incentives of Environmental Regulations: The Effects of Alternative Policy Instruments on Technology Diffusion," Journal of Environmental Economics and Management, Elsevier, vol. 29(3), pages 43-63, November.

Johnstone, Nick \& Ivan Haščič \& David Popp, 2010. "Renewable Energy Policies and Technological Innovation: Evidence Based on Patent Counts," Environmental \& Resource Economics, Springer; European Association of Environmental and Resource Economists, vol. 45(1), pages 133-155, January.

Jordà, Oscar, 2005, "Estimation and Inference of Impulse Responses by Local Projections," American Economic Review, vol. 95(1), pp. 161-182.

Lanjouw, Jean Olson \& Mody, Ashoka, 1996. "Innovation and the international diffusion of environmentally responsive technology," Research Policy, Elsevier, vol. 25(4), pages 549571, June.

Newell, Richard G. \& Adam B. Jaffe \& Robert N. Stavins, 1999. "The Induced Innovation Hypothesis and Energy-Saving Technological Change," The Quarterly Journal of Economics, Oxford University Press, vol. 114(3), pages 941-975.

Milliman, Scott R. \& Prince, Raymond, 1989. "Firm incentives to promote technological change in pollution control," Journal of Environmental Economics and Management, Elsevier, vol. 17(3), pages 247-265, November.

OECD, "How stringent are environmental policies?“, Policy Perspective (2016)

OECD (2018), "Environmental Policy Stringency index (Edition 2017)", OECD Environment Statistics (database) 
Popp, David, 2002. "Induced Innovation and Energy Prices," American Economic Review, American Economic Association, vol. 92(1), pages 160-180, March.

David Popp, 2003. "Pollution control innovations and the Clean Air Act of 1990," Journal of Policy Analysis and Management, John Wiley \& Sons, Ltd., vol. 22(4), pages 641-660.

Popp, David. 2004. "ENTICE: Endogenous Technological Change in the DICE Model of Global Warming." Journal of Environmental Economics and Management 48(1): 742-68.

Popp, David, 2006. "International innovation and diffusion of air pollution control technologies: the effects of NOX and SO2 regulation in the US, Japan, and Germany," Journal of Environmental Economics and Management, Elsevier, vol. 51(1), pages 46-71, January.

Popp, David \& Richard Newell, 2012. "Where does energy R\&D come from? Examining crowding out from energy R\&D”, Energy Economics 34 (2012) 980-991.

Popp, David \& Jacquelyn Pless \& Ivan Haščič \& Nick Johnstone, 2020. "Innovation and Entrepreneurship in the Energy Sector," NBER Working Papers 27145, National Bureau of Economic Research, Inc.

Stock, James, and Mark Watson, "Why Has U.S. Inflation Become Harder to Forecast?" Journal of Money, Banking and Credit, vol. 39(1), pp. 3-33

Taylor, Margaret. (2012). Innovation under cap-and-trade programs. Proceedings of the National Academy of Sciences of the United States of America. 109. 4804-9. 10.1073/pnas.1113462109.

Tavares, Marina M (forthcoming), "Carbon Pricing Winners and Losers: Workers, Consumers, and Policy Options", IMF Working Papers, forthcoming

Wooldridge, Jeffrey M., 1999. "Distribution-free estimation of some nonlinear panel data models," Journal of Econometrics, Elsevier, vol. 90(1), pages 77-97, May. 